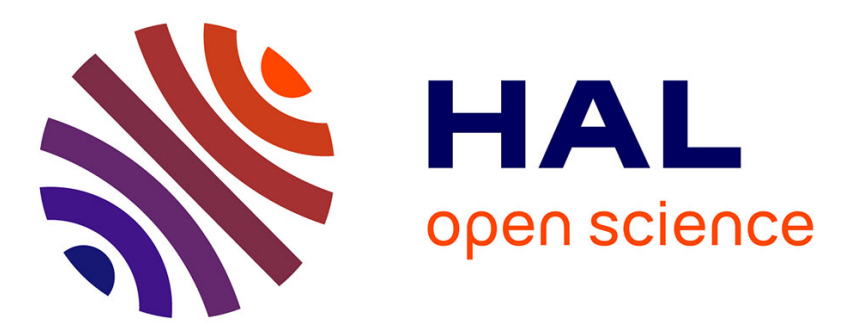

\title{
Bonding in Barium Boryloxides, Siloxides, Phenoxides and Silazides. A comparison with the lighter alkaline earths
}

Erwann Le Coz, Joanna Hammoud, Thierry Roisnel, Marie Cordier, Vincent Dorcet, Samia Kahlal, Jean-Francois Carpentier, Jean-Yves Saillard, Yann Sarazin

\section{To cite this version:}

Erwann Le Coz, Joanna Hammoud, Thierry Roisnel, Marie Cordier, Vincent Dorcet, et al.. Bonding in Barium Boryloxides, Siloxides, Phenoxides and Silazides. A comparison with the lighter alkaline earths. Chemistry - A European Journal, 2021, 27 (46), pp.11966-11982. 10.1002/chem.202101687 . hal-03282741

\section{HAL Id: hal-03282741 \\ https://hal.science/hal-03282741}

Submitted on 16 Jul 2021

HAL is a multi-disciplinary open access archive for the deposit and dissemination of scientific research documents, whether they are published or not. The documents may come from teaching and research institutions in France or abroad, or from public or private research centers.
L'archive ouverte pluridisciplinaire HAL, est destinée au dépôt et à la diffusion de documents scientifiques de niveau recherche, publiés ou non, émanant des établissements d'enseignement et de recherche français ou étrangers, des laboratoires publics ou privés. 


\section{Bonding in Barium Boryloxides, Siloxides, Phenoxides and Silazides. A comparison with the lighter alkaline earths.}

Erwann Le Coz, Joanna Hammoud, Thierry Roisnel, Marie Cordier, Vincent Dorcet, Samia Kahlal, Jean-François Carpentier, Jean-Yves Saillard,* and Yann Sarazin*

Univ Rennes, CNRS, ISCR (Institut des Sciences Chimiques de Rennes) - UMR 6226, F-35000 Rennes, France

Corresponding authors: yann.sarazin@univ-rennes1.fr jean-yves.saillard@univ-rennes1.fr

ORCID
JF. Carpentier 0000-0002-9160-7662
M. Cordier 0000-0003-0917-2725
T. Roisnel 0000-0002-6088-4472
JY. Saillard 0000-0003-4469-7922
Y. Sarazin 0000-0003-1121-0292

$\uparrow$ Electronic supplementary information (ESI) available: full experimental details, including NMR spectra; crystallographic data for CCDC 2032704-2032712, 2032967, 2033281, 2033287 and 2033317; details of DFT computations. 


\title{
Keywords
}

Barium • alkaline-earth metals $\bullet$ O-based ligands $\bullet$ DFT $\bullet$ Bonding analysis

\begin{abstract}
Barium complexes ligated by bulky boryloxides $\left[\mathrm{OBR}_{2}\right]^{-}$(where $\mathrm{R}=\mathrm{CH}\left(\mathrm{SiMe}_{3}\right)_{2}, 2,4,6-{ }^{\mathrm{i}} \mathrm{Pr}_{3}-\mathrm{C}_{6} \mathrm{H}_{2}$ or 2,4,6- $\left.\left(\mathrm{CF}_{3}\right)_{3}-\mathrm{C}_{6} \mathrm{H}_{2}\right)$, siloxide $\left[\mathrm{OSi}\left(\mathrm{SiMe}_{3}\right)_{3}\right]^{-}$, and/or phenoxide [O-2,6- $\left.\mathrm{Ph}_{2}-\mathrm{C}_{6} \mathrm{H}_{3}\right]^{-}$, have been prepared. A diversity of coordination patterns is observed in the solid state for both homoleptic and heteroleptic complexes, with coordination numbers ranging between 2 and 4 . The identity of the bridging ligand in heteroleptic dimers $\left[\mathrm{Ba}\left(\mu_{2}-\mathrm{X}_{1}\right)\left(\mathrm{X}_{2}\right)\right]$ depends largely on the given pair of ligands $\mathrm{X}_{1}$ and $\mathrm{X}_{2}$. Experimentally, the propensity to fill the bridging position increases according to $\left.\left[\mathrm{OB}\left\{\mathrm{CH}\left(\mathrm{SiMe}_{3}\right)_{2}\right\}_{2}\right)\right]^{-}$ $<\left[\mathrm{N}\left(\mathrm{SiMe}_{3}\right)_{2}\right]^{-}<\left[\mathrm{OSi}\left(\mathrm{SiMe}_{3}\right)_{3}\right]^{-}<\left[\mathrm{O}\left(2,6-\mathrm{Ph}_{2}-\mathrm{C}_{6} \mathrm{H}_{3}\right)\right]^{-}<\left[\mathrm{OB}\left(2,4,6-{ }^{-} \mathrm{Pr}_{3}-\mathrm{C}_{6} \mathrm{H}_{2}\right)_{2}\right]^{-}$. This trend is the overall expression of 3 properties: steric constraints, electronic density and $\sigma$ - and $\pi$-donating capability of the negatively charged atom, and ability to generate $\mathrm{Ba} \cdots \mathrm{F}, \mathrm{Ba} \cdots \mathrm{C}(\pi)$ or $\mathrm{Ba} \cdots \mathrm{H}-\mathrm{C}$ secondary interactions. The comparison of the structural motifs in the complexes $\left[\operatorname{Ae}\left\{\mu_{2}-\right.\right.$ $\left.\left.\mathrm{N}\left(\mathrm{SiMe}_{3}\right)_{2}\right\}\left(\mathrm{OB}\left\{\mathrm{CH}\left(\mathrm{SiMe}_{3}\right)_{2}\right\}_{2}\right)\right]_{2}(\mathrm{Ae}=\mathrm{Mg}, \mathrm{Ca}, \mathrm{Sr}$ and $\mathrm{Ba})$ suggest that these observations may be extended to all alkaline earths. DFT calculations highlight the largely prevailing ionic character of ligand-Ae bonding in all compounds. The ionic character of the Ae-ligand bond encourages bridging coordination, whereas the number of bridging ligands is controlled by steric factors. DFT computations also indicate that in $\left[\mathrm{Ba}\left(\mu_{2}-\mathrm{X}_{1}\right)\left(\mathrm{X}_{2}\right)\right]$ heteroleptic dimers, ligand predilection for bridging vs terminal positions is dictated by the ability to establish secondary interactions between the metals and the ligands.
\end{abstract}




\section{Introduction}

The heavy alkaline earths calcium, strontium and barium $(\mathrm{Ae}=\mathrm{Ca}, \mathrm{Sr}, \mathrm{Ba})$ are gaining increasing recognition as suitable alternatives in molecular catalysis to more expensive and often more toxic transition metals. ${ }^{[1-4]}$ Versatile catalysts built on these three metals have shown for example excellent performances in a panel of reactions such as the polymerisations of styrene ${ }^{[5]}$ and cyclic esters, ${ }^{[6]}$ or the hydrogenation, hydroamination and hydrophosphination of unsaturated bonds. ${ }^{[7-18]}$ Recently, they have also proved competent in catalysed dehydrocouplings for the selective formation of amidoboranes, ${ }^{[19-21]}$ silazanes, ${ }^{[22-26]}$ borasiloxanes ${ }^{[27-28]}$ and asymmetric disiloxanes. ${ }^{[29]}$ Mechanistic and kinetic investigations have revealed that for a same ligand environment, and all parameters being otherwise equal, kinetics in these catalysed reactions usually increase according to $\mathrm{Ca}<\mathrm{Sr}<\mathrm{Ba}^{[1-4]}$ A notable exception is the cyclohydroamination of aminoalkenes, where the opposite trend has been consistently observed. ${ }^{[7,30]}$ On the whole, barium hence displays the highest turnover numbers. However, it also is with this metal that the high reactivity specific of the heavy alkaline earths is most difficult to tame. ${ }^{[31]}$

Heavy alkaline-earth metals form $d^{0}$ complexes where bonding is ruled by electrostatic and steric factors, with little, or no, orbital contribution. In solution, heteroleptic complexes [\{Lig $\}$ AeX $]$, where $\{\mathrm{Lig}\}^{-}$is a monoanionic ancillary ligand and $\mathrm{X}^{-}$is often an amide, an alkyl or a hydride, often engage in ligand redistribution equilibria that generate ill-controlled mixtures unsuitable for catalysis. Stopping these phenomena, which are most troublesome for the largest and most electropositive element barium, still constitutes a challenge in modern alkaline-earth molecular chemistry. Yet, thanks to the use of carefully devised ligands, e.g. $\beta$-diketiminates, ${ }^{[12,32]}$ iminoanilides, ${ }^{[12]}$ carbazolates, ${ }^{[33-34]}$ phenoxides, ${ }^{[6,35-}$ ${ }^{36]}$ or tris(pyrazolyl)borates, ${ }^{[37]}$ the number of stable, heteroleptic barium complexes has been growing steadily in recent years. Beyond homogenous catalysis, these ligands have led to breakthroughs such as the recent preparation of soluble barium-hydrides. ${ }^{[1,37-38]}$

Despite the overall importance of alkoxides as inorganic ligands, ${ }^{[40]}$ well-defined Ba-alkoxide remain scarce due to the large size, propensity for high coordination numbers, and high oxophilicity and electropositivity of the $\mathrm{Ba}^{2+}$ dication. Conventional alcohols, e.g. ${ }^{\mathrm{t} u O H}$, yield polymeric and insoluble Ba-alkoxides. ${ }^{[35]}$ Rare examples of soluble compounds include $\left[\mathrm{Ba}\left\{\kappa^{4}-\right.\right.$ $\left.\left.\left.\mathrm{N}\left(\mathrm{CH}_{2} \mathrm{CH}_{2} \mathrm{O}\right)\left(\mathrm{CH}_{2} \mathrm{CH}_{2} \mathrm{OH}\right)_{2}\right\}_{2}\right],{ }^{[41]}\left[\mathrm{Ba}_{2}\left(\mu_{2}-\mathrm{OCPh}_{3}\right)_{3}\left(\mathrm{OCPh}_{3}\right) \text {. (thf }\right)_{3}\right]^{[42]}$ and $\left[\mathrm{Ba}\left\{\kappa^{3}-\mathrm{O}\left(\mathrm{CH}_{2} \mathrm{CH}_{2} \mathrm{O}\right)_{2}\right\}\left\{\kappa^{3}-\right.\right.$ $\left.\mathrm{O}\left(\mathrm{CH}_{2} \mathrm{CH}_{2} \mathrm{OH}\right)_{2}\right\}_{2}$ ]. ${ }^{[3]}$ The addition of $\mathrm{CF}_{3}$ groups in $\alpha$ position to the alkoxide give fluoroalkoxides with enhanced stability and solubility, as in $\left[\mathrm{Ba}\left\{\mathrm{OC}\left(\mathrm{CF}_{3}\right)_{3}\right\}_{2} \cdot(\mathrm{dme})_{3}\right] \cdot \cdot^{[44]}$

Oxygen-based derivatives of barium alkoxides exist. A number of Ba-phenoxides have been described since the report on $\left[\mathrm{Ba}\left(\mathrm{O}-2,6-{ }^{\mathrm{t}} \mathrm{Bu}_{2}-4-\mathrm{Me}-\mathrm{C}_{6} \mathrm{H}_{2}\right)(\text { thf })_{3}\right],{ }^{[45]}$ e.g. the dimer $\left[\mathrm{Ba}(\mu-\mathrm{I})\left(\mathrm{O}-2,6-{ }^{\mathrm{t}} \mathrm{Bu}_{2}{ }^{-}\right.\right.$ 4-Me- $\left.\mathrm{C}_{6} \mathrm{H}_{2}\right)$.(thf $\left.)_{3}\right]_{2}{ }^{[36]}$ or the dinuclear $\left[\mathrm{Ba}_{2}\left(\mu-\mathrm{O}-2,6-\mathrm{Ph}_{2}-\mathrm{C}_{6} \mathrm{H}_{3}\right)_{3}\left(\mathrm{O}-2,6-\mathrm{Ph}_{2}-\mathrm{C}_{6} \mathrm{H}_{3}\right)\right]{ }^{[46]}$ Siloxides have produced base-stabilised $\mathrm{Ba}$ species, such as Caulton's seminal $\left[\mathrm{Ba}_{2}\left(\mu_{2}-\mathrm{OSi}^{t} \mathrm{Bu}_{3}\right)_{3}\left(\mathrm{OSi}^{t} \mathrm{Bu}_{3}\right) \cdot\right.$ thf $],{ }^{[42]}$ and $\left[\mathrm{Ba}\left(\mathrm{OSiPh}_{3}\right)_{2}(15 \text {-crown-5).thf }]^{[47]}\right.$ or $\left.\left[\mathrm{Ba}_{3}\left(\mathrm{OSiPh}_{2} \mathrm{OSiPh}_{2} \mathrm{O}\right)_{3} \text {. (tetraglyme }\right)_{2}\right] .{ }^{[48]}$ We recently used the bulky silanol $\left(\mathrm{Me}_{3} \mathrm{Si}\right)_{3} \mathrm{SiOH}$ to generate the unsolvated Ba-siloxide $\left[\mathrm{Ba}_{2}\left\{\mu_{2}-\right.\right.$ 
$\left.\left.\mathrm{OSi}\left(\mathrm{SiMe}_{3}\right)_{3}\right\}_{3}\left\{\mathrm{OSi}\left(\mathrm{SiMe}_{3}\right)_{3}\right\}\right] \quad\left(\mathbf{1}_{2}, \quad\right.$ Figure 1$)$, and its heteroleptic congener $\left[\mathrm{Ba}\left\{\mu_{2^{-}}\right.\right.$

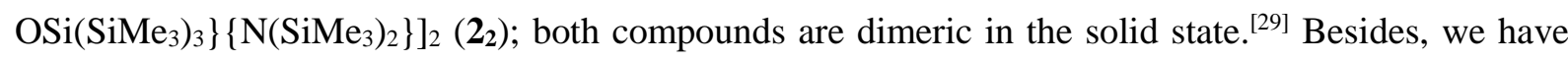
also reported the preparation and structural characterisation of the first barium boryloxides, notably the two-coordinate monomer $\left[\mathrm{Ba}\left(\mathrm{OB}\left\{\mathrm{CH}\left(\mathrm{SiMe}_{3}\right)_{2}\right\}_{2}\right)_{2}\right]$ (3) and its amido, dimeric parent $\left[\mathrm{Ba}\left\{\mu_{2}-\right.\right.$ $\left.\left.\mathrm{N}\left(\mathrm{SiMe}_{3}\right)_{2}\right\}\left(\mathrm{OB}\left\{\mathrm{CH}\left(\mathrm{SiMe}_{3}\right)_{2}\right\}_{2}\right)\right]_{2}\left(\mathbf{4}_{2}\right.$, Figure 1). ${ }^{[27]}$ We had reasoned that the presence of boron or silicon atoms would lower the $\pi$-donating ability of the $\mathrm{O}$ atoms in these ligands, and that, combined with the steric bulk imparted by multiple $\mathrm{SiMe}_{3}$ groups, they would generate soluble, low-coordinate barium complexes.

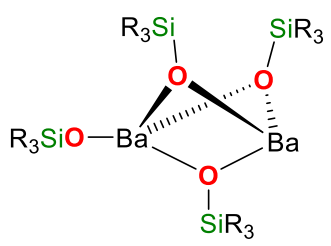

$\left(1_{2}\right)$

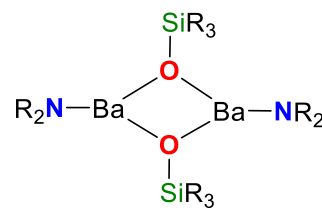

$\left(\mathbf{2}_{2}\right)$

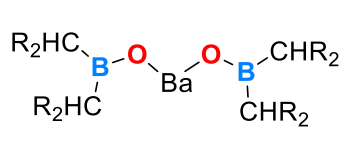

(3)

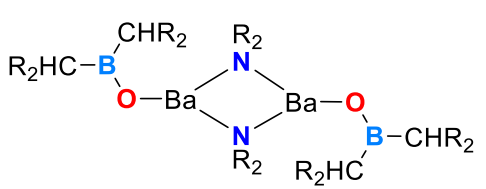

$\left(\mathbf{4}_{\mathbf{2}}\right)$

Figure 1. Solvent-free, low-coordinate barium siloxides and boryloxides; ${ }^{[27,29]} \mathrm{R}=\mathrm{SiMe}{ }_{3}$.

Although we succeeded in preparing low-coordinate complexes that proved valuable dehydrocoupling precatalysts, ${ }^{[27-29]}$ our curiosity was aroused by the variety of coordination patterns in complexes $\mathbf{1}_{2}-\mathbf{4}_{2}$. The homoleptic boryloxide $\mathbf{3}$ is monomeric, while $\mathbf{1}_{\mathbf{2}}$ is a dimer with three bridging siloxides and a single terminal one. In the heteroleptic siloxide/amide dimer $\mathbf{2}_{\mathbf{2}}$, the siloxides are bridging the two metals and the amido moieties occupies terminal position, as expected with alkaline earths and other oxophilic elements. On the other hand, the opposite situation is (uncharacteristically) observed for the boryloxide/amide $\mathbf{4}_{2}$.

As part of our continuing efforts to devise low-coordinate and reactive barium complexes suited to molecular catalysis, we are reporting here on several new homoleptic barium boryloxides. In addition, a number of heteroleptic barium complexes that combine bulky boryloxo, siloxo, phenoxo or amido ligands are also presented. The structural motifs in these compounds are analysed on the basis of X-ray diffraction crystallography, NMR spectroscopy and DFT computations, with the aim of providing an appraisal of the criteria that enable the formation of potentially useful barium precatalysts. Besides, the structural comparison in a homologous series of heteroleptic Ae-boryloxide/amide complexes is also provided. It highlights the differences in the bonding patterns involving magnesium, calcium, strontium or barium. In this context, we note that no strontium boryloxide has been reported to date, whereas the dimer $\left[\mathrm{Ca}\left\{\mu-\mathrm{OB}\left(\mathrm{CH}\left(\mathrm{SiMe}_{3}\right)_{2}\right)_{2}\right\}\left\{\mathrm{N}\left(\mathrm{C}_{6} \mathrm{~F}_{5}\right)_{2}\right\}\right]_{2}$ is the sole known calcium boryloxide. ${ }^{[49]} \mathrm{A}$ handful of magnesium congeners have been prepared before, notably the dimeric $\left[\mathrm{Mg}\left\{\mathrm{OB}(\mathrm{mes})_{2}\right\} \text { R.thf }\right]_{2}(\mathrm{R}=\mathrm{Me}$, $\mathrm{Bu}$; mes $=$ mesityl $\left.=2,4,6-\mathrm{Me}_{3}-\mathrm{C}_{6} \mathrm{H}_{2}\right)^{[50]}$ and the $\beta$-diketiminato $\left[\left\{\mathrm{BDI}^{\mathrm{DiPP}}\right\} \mathrm{MgOBPh}_{2}\right.$. $\left.(\mathrm{L})\right]$, where $\mathrm{L}$ is either a neutral organoboronic ester or $N, N$-dimethylaminopyridine. ${ }^{[51]}$ 


\section{Results and Discussion}

Synthesis of homoleptic barium boryloxides

Prior to this work, existing barium boryloxides were limited to $\mathbf{3}, \mathbf{4}_{2}$ and to the solvated $\mathbf{3}$.toluene and 3.(thf $)_{2} \cdot{ }^{[27,29,52]} \mathrm{We}$ set out to prepare new complexes using the borinic acids $\left\{\left(\mathrm{Me}_{3} \mathrm{Si}\right)_{2} \mathrm{CH}\right\}_{2} \mathrm{BOH},{ }^{[53]}$ (mes) ${ }_{2} \mathrm{BOH},{ }^{[54-55]}$ (Tripp) ${ }_{2} \mathrm{BOH},{ }^{[54-55]}\{\text { Fmes }\}_{2} \mathrm{BOH}^{[56]}$ and $\left(\mathrm{C}_{6} \mathrm{~F}_{5}\right)_{2} \mathrm{BOH}^{[57-59]}$ (Tripp = 2,4,6- $-{ }^{\mathrm{i}} \mathrm{Pr}_{3}-\mathrm{C}_{6} \mathrm{H}_{2}$, Fmes $=2,4,6-\left(\mathrm{CF}_{3}\right)_{3}-\mathrm{C}_{6} \mathrm{H}_{2}$, Scheme 1). These known compounds were prepared on multigram scales and high yields upon modification of published protocols. All are crystalline colourless solids with good solubility in organic solvents. Their identity was confirmed by NMR spectroscopy and X-ray diffraction crystallography (see the Supporting Information, Figures S49-S53). They are monomeric in the solid state, except for $\left(\mathrm{C}_{6} \mathrm{~F}_{5}\right)_{2} \mathrm{BOH}$ which forms a cyclic trimer with a non-planar $\mathrm{B}_{3} \mathrm{O}_{3}$ core; yet, it is monomeric in solution in toluene- $d_{8}$ at room temperature. ${ }^{[60]}$ Their respective chemical shifts in ${ }^{11} \mathrm{~B}$ NMR $\left(\delta_{11 \mathrm{~B}} 53.8,50.8,52.2,43.5\right.$ and $40.5 \mathrm{ppm}$ in benzene- $\left.d_{6}\right)$ are in the range expected for trivalent boron atoms. The borinic acids with lower electronic density at boron, $\{\text { Fmes }\}_{2} \mathrm{BOH}$ and $\left(\mathrm{C}_{6} \mathrm{~F}_{5}\right)_{2} \mathrm{BOH}$, are the most shielded.

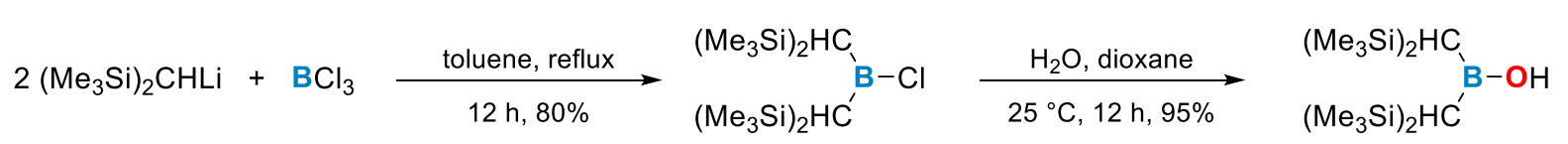

2<smiles>[R]c1cc([R])c(Br)c([R])c1</smiles><smiles>FC(F)(F)c1cc(C(F)(F)F)cc(C(F)(F)F)c1</smiles>

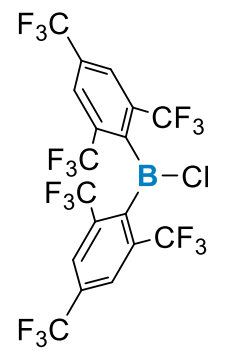

$$
\mathrm{R}=\mathrm{Me} \quad 81 \%
$$

íPr $85 \%$

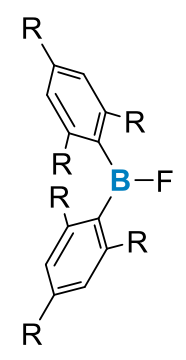

$\underset{\mathrm{C}_{6}}{\mathrm{C}_{6}} \mathrm{~F}_{5}^{\mathrm{F}}$

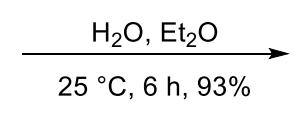

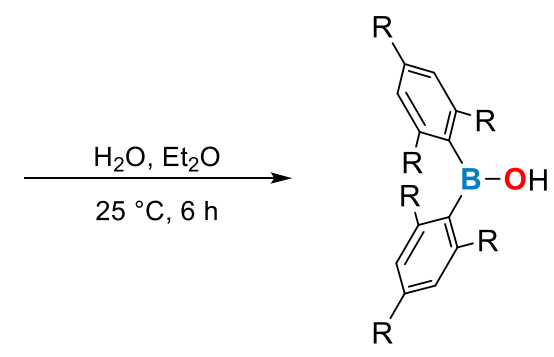

$\mathrm{R}=\mathrm{Me} \quad 93 \% \quad(\text { mes })_{2} \mathrm{BOH}$

${ }^{\mathrm{i}} \mathrm{Pr} \quad 94 \% \quad(\text { Tripp })_{2} \mathrm{BOH}$

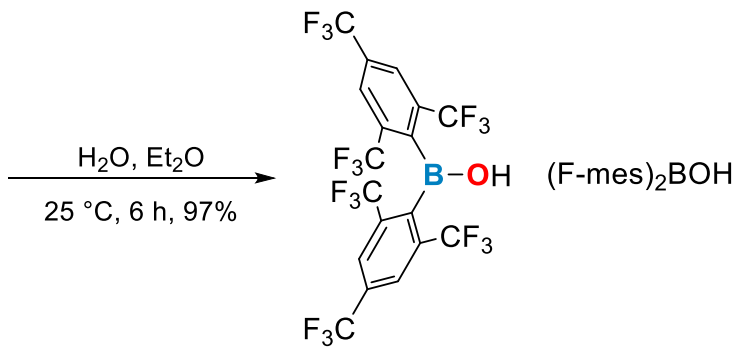

$\mathrm{F}_{3} \mathrm{C}$

$\mathrm{Me}_{2} \mathrm{Sn}\left(\mathrm{C}_{6} \mathrm{~F}_{5}\right)_{2}+\mathrm{BCl}_{3} \underset{24 \mathrm{~h}, 81 \% \text { (sublimed) }}{\stackrel{\text { toluene, }-78^{\circ} \mathrm{C} \text { to reflux }}{\longrightarrow}}$

Scheme 1. Optimised syntheses of borinic acids. ${ }^{[53-59]}$ 
Following the synthesis of $\left[\mathrm{Ba}\left(\mathrm{OB}\left\{\mathrm{CH}\left(\mathrm{SiMe}_{3}\right)_{2}\right\}_{2}\right)_{2}\right](3),{ }^{[27]}$ a monomer stabilised by intra- and intermolecular $\mathrm{Ba} \cdots \mathrm{H}-\mathrm{C}$ interactions, we were interested in obtaining other low-coordinate $\mathrm{Ba}$ boryloxides to assess the role of secondary interactions towards the stabilisation of electrophilic barium complexes. Our initial attempts started off with (mes) ${ }_{2} \mathrm{BOH}$, but it failed to react with $\left[\mathrm{Ba}\left\{\mathrm{N}\left(\mathrm{SiMe}_{3}\right)_{2}\right\}_{2}\right]_{2}$ or $\left.\left[\mathrm{Ba}\left\{\mathrm{N}\left(\mathrm{SiMe}_{3}\right)_{2}\right\}_{2} \text {. (thf }\right)_{2}\right]$. Beyond the fact that this borinic acid is prone to condensation with loss of $\mathrm{H}_{2} \mathrm{O}$ and concomitant formation of (mes) $)_{2} \mathrm{~B}-\mathrm{O}-\mathrm{B}(\text { mes })_{2}$, the several reactions that were carried out only afforded the oxocluster $\left[\mathrm{Ba}_{4}(\mathrm{O})\left\{\mathrm{OB}(\mathrm{mes})_{2}\right\}_{6}\right]$ as the sole isolable product, probably due to the release of water in the reaction medium. This cluster, a colourless crystalline material, was authenticated by $\mathrm{XRD}$ analysis (Figure S54). The reactivity of (mes) ${ }_{2} \mathrm{BOH}$ observed here is different from that with more robust magnesium precursors, although the reported synthesis of $\left[\mathrm{Mg}\left\{\mathrm{OB}(\mathrm{mes})_{2}\right\} \mathrm{Me} \text {.(thf) }\right]_{2}$ was said to be erratic and to give low yields. ${ }^{[50]} \mathrm{We}$ were also unable to obtain Ba-boryloxides from the electronpoor $\left(\mathrm{C}_{6} \mathrm{~F}_{5}\right)_{2} \mathrm{BOH}$. Regardless of the conditions, all attempted reactions generated intractable mixtures of compounds which contained various borates, as indicated by ${ }^{11} \mathrm{~B}$ NMR spectroscopy (multiple resonances in the range -5 to $-20 \mathrm{ppm})$. On the other hand, treatment of $\left.\left[\mathrm{Ba}\left\{\mathrm{N}\left(\mathrm{SiMe}_{3}\right)_{2}\right\}_{2} \text {. (thf }\right)_{2}\right]$ in toluene with two equivalents of (Tripp) ${ }_{2} \mathrm{BOH}$ returned the thf-free dimer $\left[\mathrm{Ba}\left\{\mu_{2}-\right.\right.$ $\left.\left.\mathrm{OB}(\text { Tripp })_{2}\right\}\left\{\mathrm{OB}(\text { Tripp })_{2}\right\}\right]_{2}$ in $74 \%$ yield $\left(\mathbf{5}_{2}\right.$, Scheme 2$)$. The identical reaction with $\{\text { Fmes }\}_{2} \mathrm{BOH}$ produced the thf-adduct $\left.\left[\mathrm{Ba}\left\{\mu_{2}-\mathrm{OB}(\text { Fmes })_{2}\right\}\left\{\mathrm{OB}(\mathrm{Fmes})_{2}\right\} \text {.thf }\right]_{2}\left(\boldsymbol{6}_{2} \text {. (thf }\right)_{2}\right)$, whereas the unsolvated $\left[\mathrm{Ba}\left\{\mu_{2}-\mathrm{OB}(\mathrm{Fmes})_{2}\right\}\left\{\mathrm{OB}(\mathrm{Fmes})_{2}\right\}\right]_{2}\left(\boldsymbol{6}_{2}\right)$ was isolated near quantitatively following the stoichiometric reaction of $\{\text { Fmes }\}_{2} \mathrm{BOH}$ with thf-free $\left[\mathrm{Ba}\left\{\mathrm{N}\left(\mathrm{SiMe}_{3}\right)_{2}\right\}_{2}\right]_{2}$. Both these complexes are sparingly soluble in aromatic and aliphatic hydrocarbons.

The colourless complexes $\mathbf{5}_{\mathbf{2}}, \mathbf{6}_{\mathbf{2}}$ and $\mathbf{6}_{\mathbf{2}}$. (thf) $)_{2}$ were characterised by NMR spectroscopy and XRDdiffraction analysis performed on single crystals. The NMR data for $\mathbf{5}_{\mathbf{2}}$ confirm the absence of thf in the complex. The ${ }^{1} \mathrm{H}$ NMR spectrum recorded in benzene- $d_{6}$ shows broad, ill-defined resonances that testify to dynamic phenomena in solution in this solvent, assumed to result from the rotation of ${ }^{i} \mathrm{Pr}$ groups or coordination-dissociation of aromatic molecules, rather than a monomer-dimer equilibrium for which no evidence could be found. The ${ }^{1} \mathrm{H}$ NMR spectrum recorded in thf- $d_{8}$ only shows sharp resonances and confirms the identity and purity of $\mathbf{5}_{2}$. The ${ }^{11} \mathrm{~B}$ spectrum in thf- $d_{8}$ features a single resonance at 47.1 $\mathrm{ppm}$. Due to their limited solubility, the NMR data for $\mathbf{6}_{\mathbf{2}}$ and $\mathbf{6}_{2}$.(thf) $)_{2}$ were both recorded in thf- $d_{8}$, and the two sets of NMR resonances in this solvent are hence unsurprisingly identical. The ${ }^{19} \mathrm{~F}$ NMR spectra only exhibit two sharp singlets at $\delta_{19 \mathrm{~F}}-56.58$ and $-63.98 \mathrm{ppm}$ (ortho- and para- $\mathrm{CF}_{3}$ groups, respectively). A unique resonance appears at $\delta_{11 \mathrm{~B}} 34.1 \mathrm{ppm}$ in the ${ }^{11} \mathrm{~B}$ NMR spectra. There is no indication that the dimeric structure of these three complexes is maintained in thf- $d_{8}$, and we could not detect any evidence for the presence of $\mathrm{Ba} \cdots \mathrm{F}$ or $\mathrm{Ba} \cdots \mathrm{C}(\pi)$ interactions (see below). 


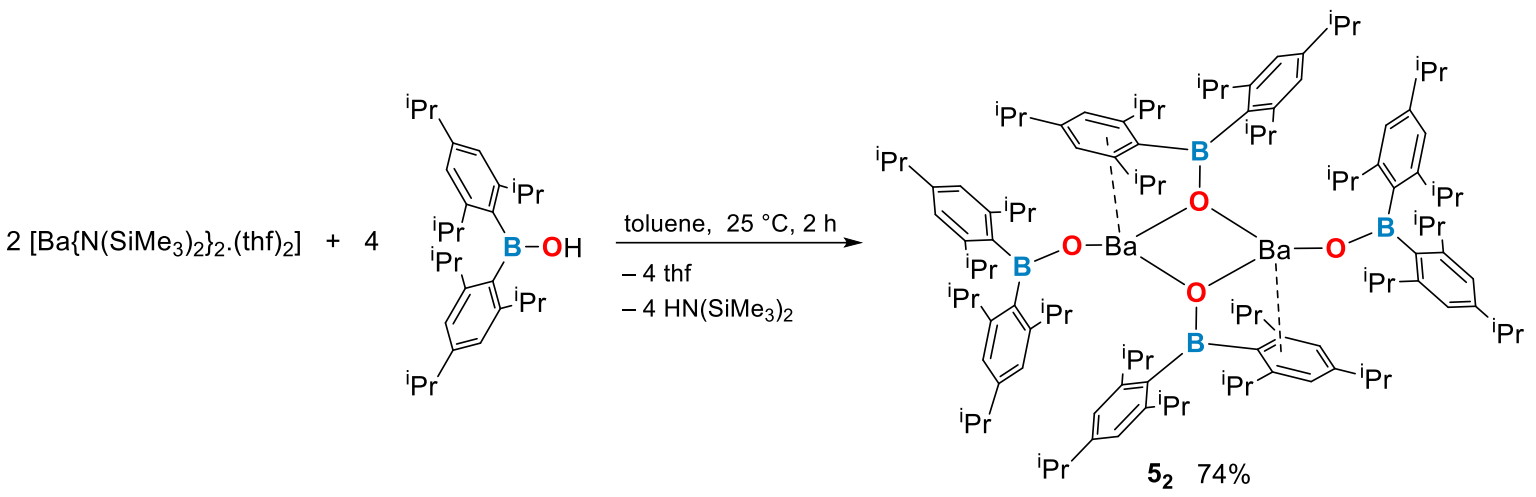

(A) $2\left[\mathrm{Ba}\left\{\mathrm{N}\left(\mathrm{SiMe}_{3}\right)_{2}\right\}_{2} \cdot(\text { thf })_{2}\right]$

(B) $\left[\mathrm{Ba}\left\{\mathrm{N}\left(\mathrm{SiMe}_{3}\right)_{2}\right\}_{2}\right]_{2}$
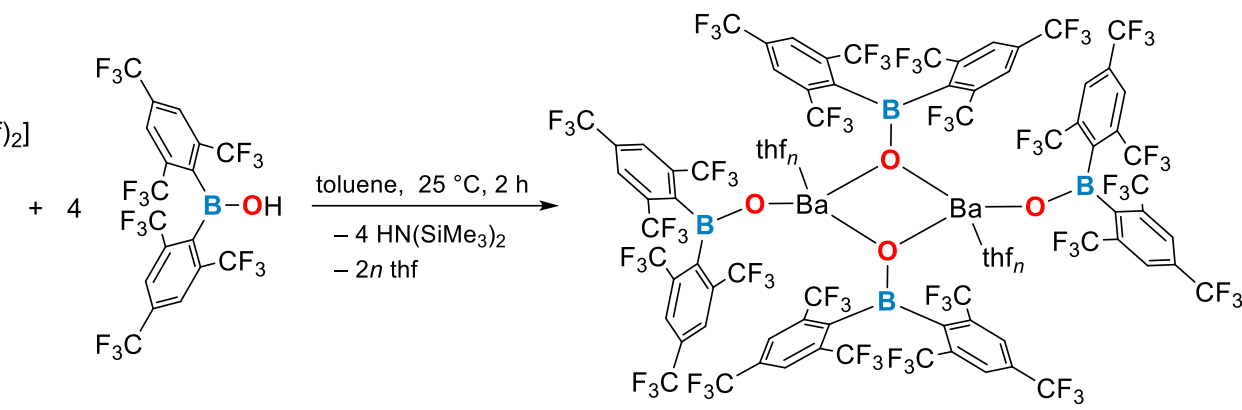

(A) $n=1 \quad \mathbf{6}_{2}$.(thf) $)_{2} \quad 89 \%$

(B) $n=\begin{array}{lll}n & 6_{2} & 91 \%\end{array}$

Scheme 2. Synthesis of homoleptic barium boryloxides.

The molecular solid-state structure of $\mathbf{5}_{\mathbf{2}}$ is depicted in Figure 2. The complex is a centrosymmetric O-bridged dimer with a rhomboidal $\mathrm{Ba}_{2} \mathrm{O}_{2}$ core. Each barium is three-coordinate in a distorted trigonal pyramidal geometry $\left(\Sigma_{\theta}(\mathrm{Ba} 1)=320.03(7)^{\circ}\right)$. This pyramidalisation results from the presence of $\mathrm{Ba} \cdots \mathrm{C}(\pi) \eta^{3}$-interactions, with $\mathrm{Ba}-\mathrm{C}$ interatomic distances in the range 3.0854(15)3.3157(16) $\AA$ to three flanking C-atoms in a Tripp moiety carried by the bridging ligand. Only one aromatic group engages in the $\eta^{3}$-interaction with each barium centre. Correspondingly, the Ba1-O1 ${ }^{\text {i- }}$ $\mathrm{B} 1^{1}$ angle for the $\mathrm{B}$ and $\mathrm{B}$-atom bearing the interacting Tripp group $\left(105.40(9)^{\circ}\right)$ is much narrower than the two other Ba-O-B angles $\left(143.11(10)^{\circ}\right.$ and $\left.148.28(11)^{\circ}\right)$, while the angle $\mathrm{O} 1^{\mathrm{i}}-\mathrm{B} 1^{\mathrm{i}}-\mathrm{C} 2^{\mathrm{i}}$ is also substantially lower than $\mathrm{O} 1^{\mathrm{i}}-\mathrm{B} 1^{\mathrm{i}}-\mathrm{C} 17^{\mathrm{i}}\left(112.54(13)^{\circ}\right.$ and $\left.122.23(13)^{\circ}\right)$. The $\mathrm{C} 2^{\mathrm{i}}-\mathrm{C} 3^{\mathrm{i}}$ and $\mathrm{C} 2^{\mathrm{i}}-\mathrm{C} 7^{\mathrm{i}}$ interatomic distances (1.423(2) and 1.414(2) $\AA$ ) for the $\mathrm{C} 2{ }^{\mathrm{i}}, \mathrm{C} 3^{\mathrm{i}}$ and $\mathrm{C}^{\mathrm{i}}$ involved in the $\pi$-coordination with $\mathrm{Ba} 1$ are a little stretched compared to the other $\mathrm{C}=\mathrm{C}$ bonds in the aromatic fragment (1.397(2)$1.402(2) \AA)$. Both boron atoms are in ideal trigonal planar environments.

The molecular structure of $\mathbf{6}_{\mathbf{2}}$ displayed in Figure 3 shows this complex to also exist as an Obridged dimer with three-coordinate barium atoms. The complex is stabilised by a pattern of secondary $\mathrm{Ba} \cdots \mathrm{F}$ interactions, with corresponding interatomic distances in the range 2.932(2)-3.284(3) $\AA$ well below the sum of Van der Waals radii for Ba and F (2.67 and 1.47 $\AA$ ). Each Ba engages in up to seven intramolecular contacts within a dimeric motif, as well as an intermolecular interaction with a neighbouring molecule $\left(\mathrm{Ba} 1-\mathrm{F} 40^{\mathrm{iii}}=2.957(3) \AA\right)$. The presence of the intermolecular contacts leads to 
the formation of one-dimensional coordination polymers in the solid state, although there is no spectroscopic indication that this arrangement is maintained in solution.

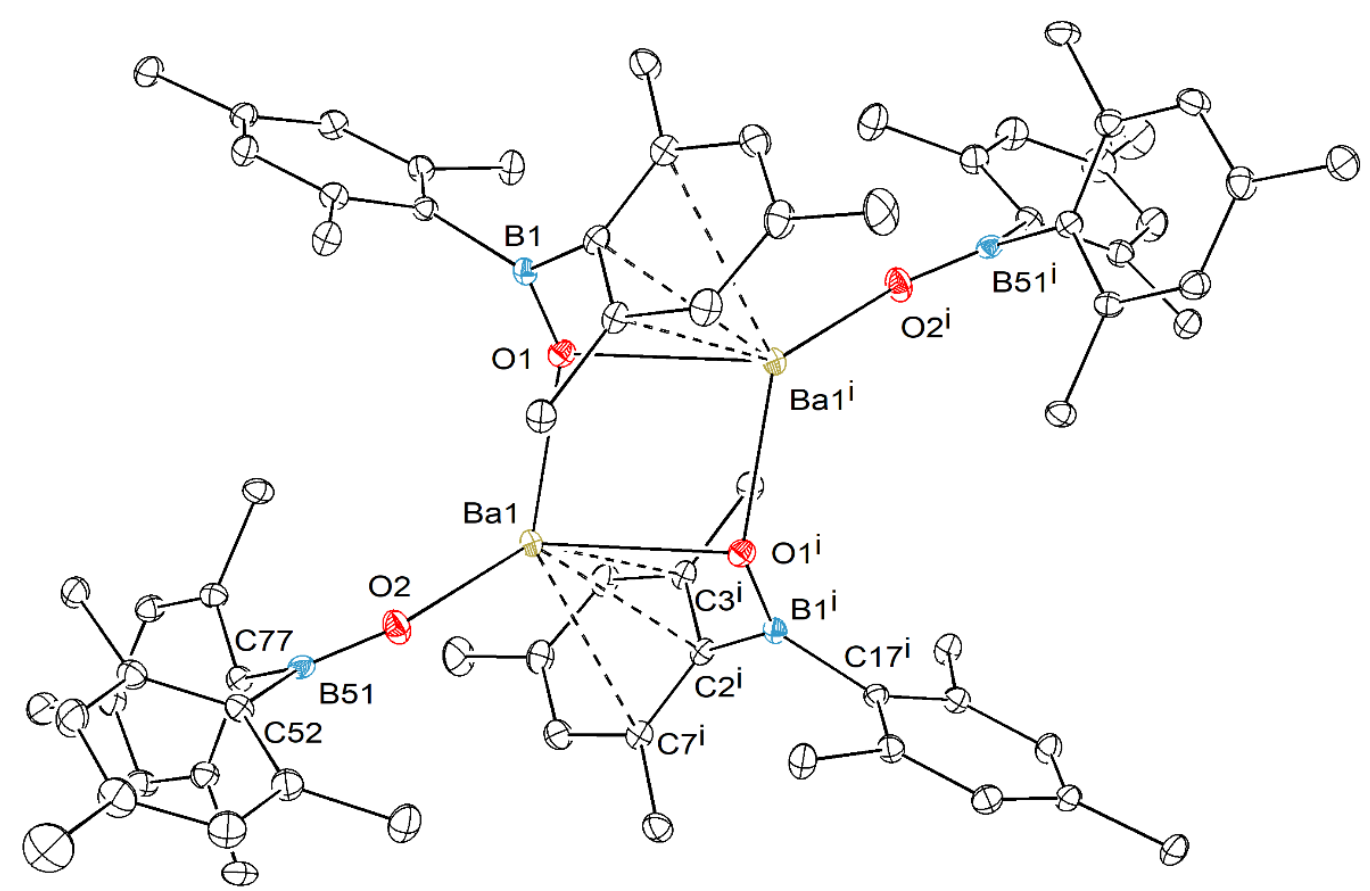

Figure 2. ORTEP representation of the molecular structure of $\left[\mathrm{Ba}\left\{\mu_{2}-\mathrm{OB}(\mathrm{Tripp})_{2}\right\}\left\{\mathrm{OB}(\mathrm{Tripp})_{2}\right\}\right]_{2}\left(\mathbf{5}_{2}\right)$. Noninteracting toluene molecule, $\mathrm{H}$ atoms and Me groups not represented for the sake of clarity. Ellipsoids at the 50\% probability level. $\mathrm{Ba} \cdots \mathrm{C}(\pi)$ interactions depicted with dashed lines. Selected interatomic distances $(\AA)$ and angles $\left({ }^{\circ}\right): \mathrm{Ba} 1-\mathrm{O} 1=2.5694(11), \mathrm{Ba} 1-\mathrm{O} 1^{\mathrm{i}}=2.8100(11), \mathrm{Ba} 1-\mathrm{O} 2=2.4167(11), \mathrm{Ba} 1-\mathrm{C} 2^{\mathrm{i}}=3.0854(15), \mathrm{Ba} 1-\mathrm{C} 3^{\mathrm{i}}=$

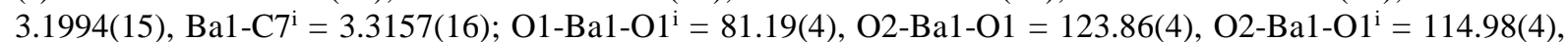
$\mathrm{Ba} 1-\mathrm{O} 1-\mathrm{B} 1=143.11(10), \mathrm{Ba} 1-\mathrm{O} 1^{\mathrm{i}}-\mathrm{B} 1^{\mathrm{i}}=105.40(9), \mathrm{Ba} 1-\mathrm{O} 1-\mathrm{Ba} 1^{\mathrm{i}}=98.82(4), \mathrm{Ba} 1-\mathrm{O} 2-\mathrm{B} 51=148.28(11), \mathrm{O} 1^{\mathrm{i}}-$ $\mathrm{B} 1^{\mathrm{i}}-\mathrm{C} 2^{\mathrm{i}}=112.54(13), \mathrm{O} 1^{\mathrm{i}}-\mathrm{B} 1^{\mathrm{i}}-\mathrm{C} 17^{\mathrm{i}}=122.23(13)$. Symmetry transformations used to generate equivalent atoms: $\mathrm{i},-\mathrm{x},-\mathrm{y},-\mathrm{z}, \mathrm{T}=[1,0,0]$.

The structure of the dimeric solvate $\mathbf{6}_{2}$. (thf) $)_{2}$ shares some common features with that of $\mathbf{6}_{2}$, namely the presence of multiple intramolecular Ba $\cdots \mathrm{F}$ contacts (Figure S46). However, due to the coordination of thf molecules, each metal is now four-coordinate, and does not feature intermolecular Ba $\cdots \mathrm{F}$ interaction; as a result, in contrast with $\mathbf{6}_{2}, \mathbf{6}_{2}$. (thf) $)_{2}$ shares does not form a coordination polymer. As suggested by Ruhlandt-Senge over a decade ago, ${ }^{[61]} \mathrm{Ae} \cdots \mathrm{F}-\mathrm{C}$ secondary interactions such as in $\mathbf{6}_{\mathbf{2}}$ and $\mathbf{6}_{2}$. (thf) $)_{2}$ constitute an efficient tool (along other types of secondary interactions, e.g. anagostic Ae $\cdots \mathrm{H}$ or, as above in $\mathbf{5}_{2}, \mathrm{Ae} \cdots \mathrm{C}(\boldsymbol{\pi})$ ) towards the stabilisation of low-coordinate alkaline-earth complexes. It has been used effectively to obtain a variety of highly electrophilic Ae species in recent years. ${ }^{[6,49,62,63]}$ 


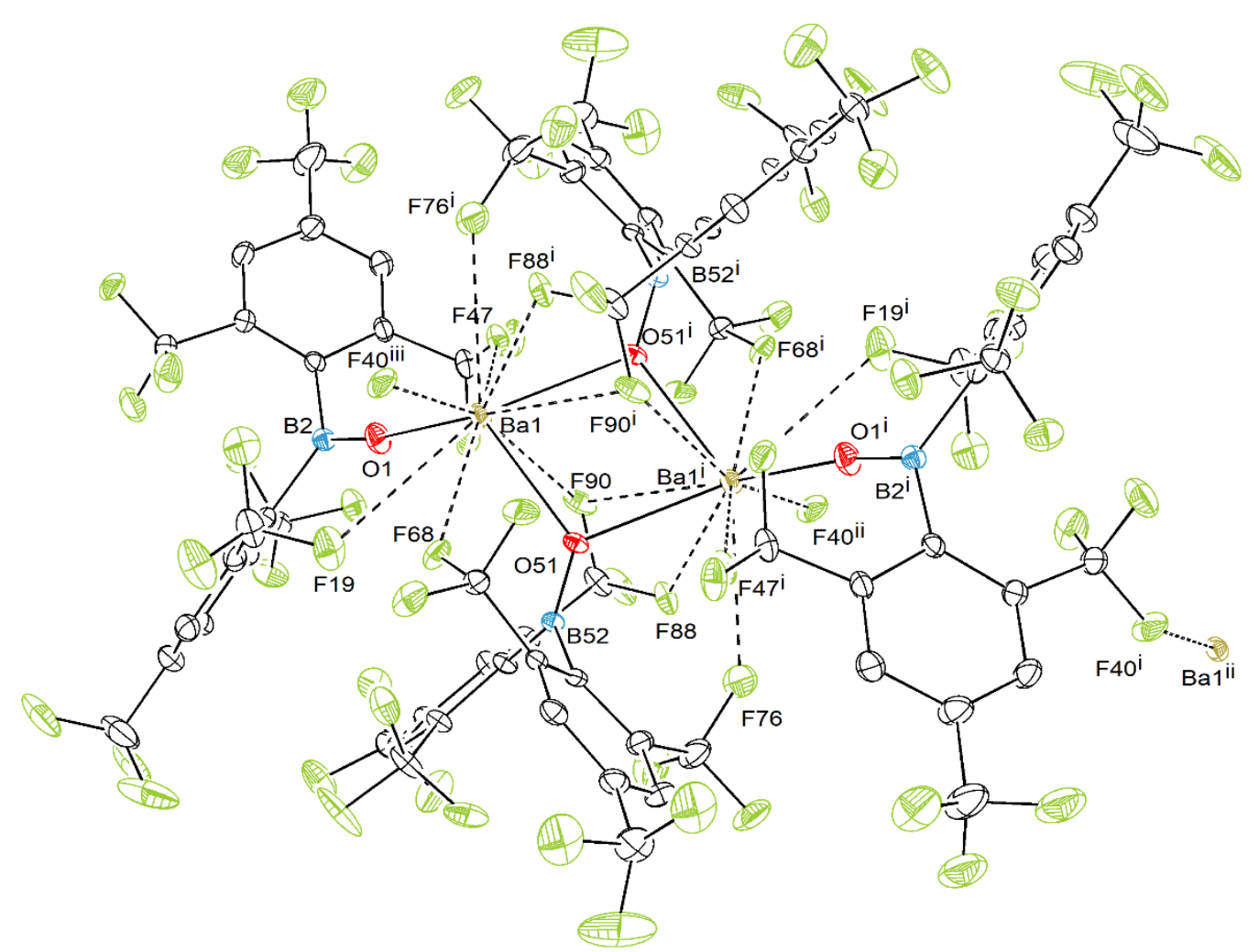

Figure 3. ORTEP representation of the molecular structure of $\left[\mathrm{Ba}\left\{\mu_{2}-\mathrm{OB}(\mathrm{Fmes})_{2}\right\}\left\{\mathrm{OB}(\mathrm{Fmes})_{2}\right\}\right]_{2}\left(\mathbf{6}_{2}\right)$. H atoms omitted for clarity. Ellipsoids at the $30 \%$ probability level. Selected interatomic distances $(\AA)$ and angles $\left({ }^{\circ}\right)$ : Ba1$\mathrm{O} 1=2.435(3), \mathrm{Ba} 1-\mathrm{O} 51=2.623(3), \mathrm{Ba} 1-\mathrm{O} 51^{\mathrm{i}}=2.657(3), \mathrm{Ba} 1-\mathrm{F} 19=3.218(4), \mathrm{Ba} 1-\mathrm{F} 40^{\mathrm{iii}}=2.957(3), \mathrm{Ba} 1-\mathrm{F} 47=$ 3.104(3), Ba1-F68 = 3.284(3), Ba1-F76 = 3.164(3), Ba1-F88 = 2.933(2), Ba1-F90 = 2.939(3); Ba1-O1-B2 = 171.9(3), Ba1-O51-Ba $1^{\mathrm{i}}=104.45(9)$. Symmetry transformations used to generate equivalent atoms: $\mathrm{i},-\mathrm{x},-\mathrm{y},-\mathrm{z}$, $\mathrm{T}=[1,0,0] ;$ ii, $-\mathrm{x},-\mathrm{y},-\mathrm{z}, \mathrm{T}=[0,0,0]$.

\section{Synthesis of heteroleptic barium complexes}

The synthesis of barium complexes was extended to heteroleptic boryloxides and other related species, namely phenoxides and siloxides (Scheme 3), to complement the first examples of these compounds recently introduced: the amido-bridged dimer $\left[\mathrm{Ba}\left\{\mu_{2}-\mathrm{N}\left(\mathrm{SiMe}_{3}\right)_{2}\right\}\left(\mathrm{OB}\left\{\mathrm{CH}\left(\mathrm{SiMe}_{3}\right)_{2}\right\}_{2}\right)\right]_{2}\left(\mathbf{4}_{2}\right),{ }^{[27]}$ and the dinuclear $\left[\mathrm{Ba}\left\{\mu_{2}-\mathrm{OSi}\left(\mathrm{SiMe}_{3}\right)_{3}\right\}\left\{\mathrm{N}\left(\mathrm{SiMe}_{3}\right)_{2}\right\}\right]_{2}\left(\mathbf{2}_{2}\right)$ bridged by a siloxide. ${ }^{[29]}$ The ambition was to assess which of the bulky boryloxides, the siloxide $\left(\mathrm{Me}_{3} \mathrm{Si}\right) \mathrm{SiO}^{-}$and the regular hexamethyldisilazide $\left(\mathrm{Me}_{3} \mathrm{Si}\right)_{2} \mathrm{~N}^{-}$would provide suitable electronic density and/or steric shielding to generate solvent-free barium and perhaps, by extrapolation, other alkaline-earth complexes.

All reactions described here were carried out in toluene at room temperature. The boryloxidebridged $\left[\mathrm{Ba}\left\{\mu_{2}-\mathrm{OB}(\mathrm{Tripp})_{2}\right\}\left\{\mathrm{N}\left(\mathrm{SiMe}_{3}\right)_{2}\right\}\right]_{2}\left(\mathbf{7}_{2}\right)$ was isolated in $67 \%$ yield following the equimolar reaction of $\left.\left[\mathrm{Ba}\left\{\mathrm{N}\left(\mathrm{SiMe}_{3}\right)_{2}\right\}_{2} \text {. (thf }\right)_{2}\right]$ with (Tripp $)_{2} \mathrm{BOH}$. Treatment of $\mathbf{2}_{2}$ with two equivalents of $\left\{\left(\mathrm{Me}_{3} \mathrm{Si}\right)_{2} \mathrm{CH}\right\}_{2} \mathrm{BOH}$ afforded the quantitative and selective formation of the siloxo-bridged $\left[\mathrm{Ba}\left\{\mu_{2}-\right.\right.$ $\left.\left.\mathrm{OSi}\left(\mathrm{SiMe}_{3}\right)_{3}\right\}\left(\mathrm{OB}\left\{\mathrm{CH}\left(\mathrm{SiMe}_{3}\right)_{2}\right\}_{2}\right)\right]_{2}\left(\mathbf{8}_{2}\right)$ upon release of $\mathrm{HN}\left(\mathrm{SiMe}_{3}\right)_{2}$. The analogous reaction between $\mathbf{2}_{2}$ and the aromatic borinic acid (Tripp) ${ }_{2} \mathrm{BOH}$ yielded the dimer $\left[\mathrm{Ba}\left\{\mu_{2}-\mathrm{OB}(\mathrm{Tripp})_{2}\right\}\left\{\mathrm{OSi}\left(\mathrm{SiMe}_{3}\right)_{3}\right\}\right]_{2}$ $\left(\mathbf{9}_{2}\right)$, where the two metals are bridged by the boryloxides. Finally, the mixed siloxide/phenoxide $\left[\mathrm{Ba}\left\{\mu_{2}-\right.\right.$ $\left.\left.\mathrm{O}\left(2,6-\mathrm{Ph}_{2}-\mathrm{C}_{6} \mathrm{H}_{3}\right)\right\}\left\{\mathrm{OSi}\left(\mathrm{SiMe}_{3}\right)_{3}\right\}\right]_{2}\left(\mathbf{1 0}_{2}\right)$ was obtained in $70 \%$ yield upon protonolysis of $\mathbf{2}_{\mathbf{2}}$ with two 
equivalents of 2,6- $\mathrm{Ph}_{2}-\mathrm{C}_{6} \mathrm{H}_{3}-\mathrm{OH}$. On the other hand, our attempts to synthesise heteroleptic boryloxide/phenoxide species starting from $\mathbf{4}_{\mathbf{2}}$ or $\mathbf{7}_{\mathbf{2}}$ were unsuccessful. All four heteroleptic complexes $\mathbf{7}_{\mathbf{2}}-\mathbf{1 0}_{\mathbf{2}}$ were obtained as colourless solids, and were recrystallised as single crystals suitable for XRD analysis. Compound $\mathbf{8}_{2}$ is very soluble in all organic solvents, but $\mathbf{7}_{\mathbf{2}}$ and especially $\mathbf{9}_{2}$ and $\mathbf{1 0}_{\mathbf{2}}$ have limited solubility in hydrocarbons, including aromatic ones.
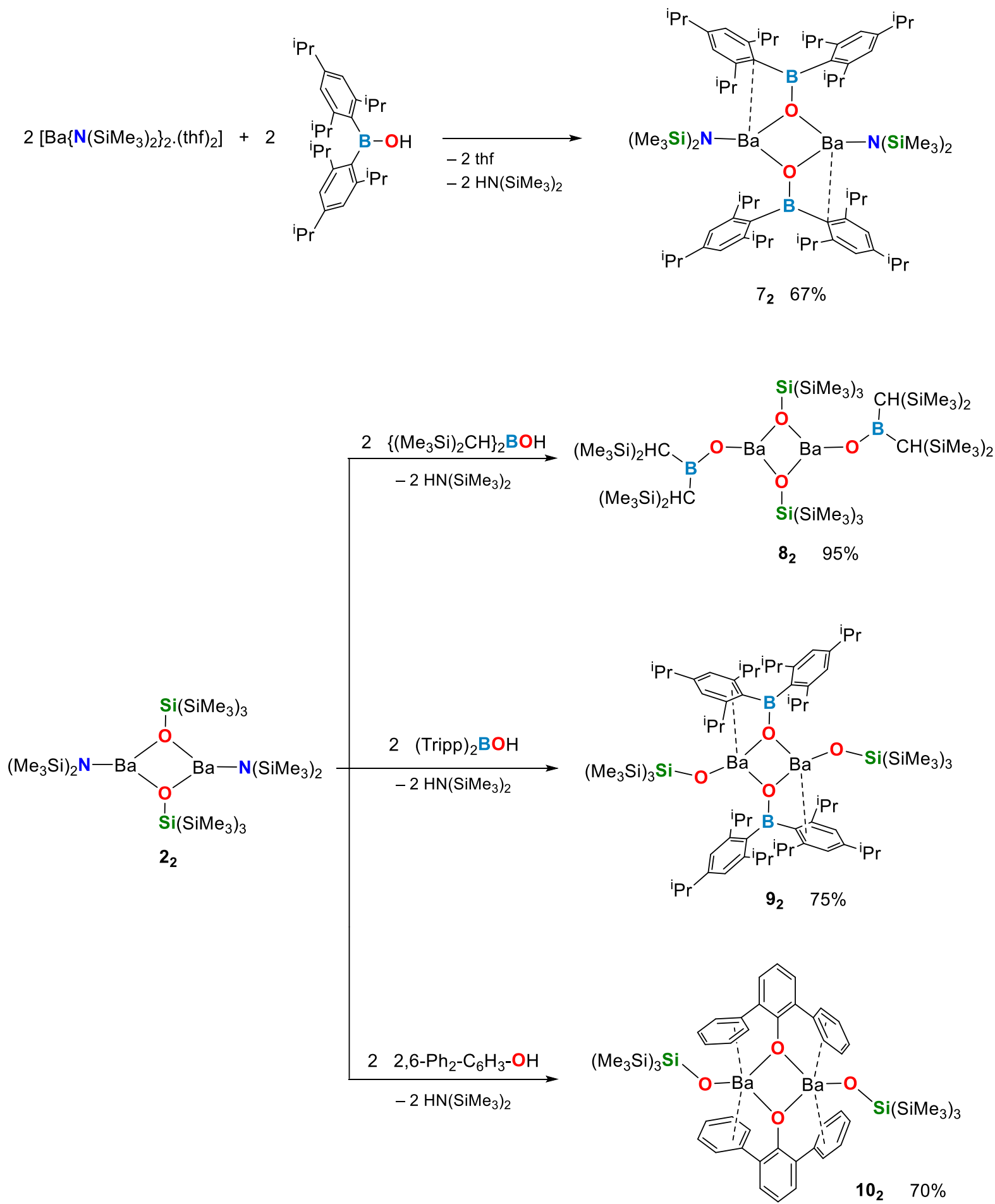

Scheme 3. Synthesis of boryloxo/siloxo/phenoxo/amido heteroleptic barium complexes $\mathbf{7 2}_{\mathbf{2}} \mathbf{- 1 0 2}$. 
The NMR spectroscopic data recorded for crystalline materials in benzene- $d_{6}$ (for $\mathbf{7}_{\mathbf{2}}$ and $\mathbf{8}_{\mathbf{2}}$ ) and thf- $d_{8}$ (for $\mathbf{9}_{2}$ and $\mathbf{1 0}_{2}$ ) are unremarkable. Most ${ }^{11} \mathrm{~B}$ and ${ }^{29} \mathrm{Si}$ resonances could be located, except in two cases, for $\mathbf{9}_{2}$ and $\mathbf{1 0}_{2}$, most probably due to high fluxionality of the systems in solution; low temperature NMR provided no assistance. A summary of representative NMR data for these complexes, as well as those for the homoleptic complexes described herein and for complexes $\mathbf{1}_{\mathbf{2}} \mathbf{-} \mathbf{4}_{\mathbf{2}}$, is collated in Table 1 .

Table 1. Multinuclear NMR data for complexes $\mathbf{1}_{2}-\mathbf{1 0}$. Data for $\mathbf{1} \mathbf{1}_{\mathbf{2}} \mathbf{4}$ are taken from references [27-29].

\begin{tabular}{|c|c|c|c|c|c|}
\hline Complex & & Solvent & $\begin{array}{c}{ }^{19} \text { F NMR } \\
(\mathrm{ppm})\end{array}$ & $\begin{array}{c}{ }^{11} \mathrm{~B} \text { NMR } \\
(\mathrm{ppm})\end{array}$ & $\begin{array}{c}{ }^{29} \mathrm{Si} \mathrm{NMR} \\
(\mathrm{ppm})\end{array}$ \\
\hline$\left[\mathrm{Ba}_{2}\left\{\mu_{2}-\mathrm{OSi}\left(\mathrm{SiMe}_{3}\right)_{3}\right\}_{3}\left\{\mathrm{OSi}\left(\mathrm{SiMe}_{3}\right)_{3}\right\}\right]$ & $\mathbf{1}$ & benzene- $d_{6}$ & - & - & $\begin{array}{l}-19.37 \\
-27.02\end{array}$ \\
\hline$\left[\mathrm{Ba}\left\{\mu_{2}-\mathrm{OSi}\left(\mathrm{SiMe}_{3}\right)_{3}\right\}\left\{\mathrm{N}\left(\mathrm{SiMe}_{3}\right)_{2}\right\}\right]_{2}$ & $\mathbf{2}_{2}$ & benzene- $d_{6}$ & - & - & $\begin{array}{l}-18.60 \\
-19.22 \\
-19.27 \\
-24.69 \\
-27.74\end{array}$ \\
\hline$\left[\mathrm{Ba}\left(\mathrm{OB}\left\{\mathrm{CH}\left(\mathrm{SiMe}_{3}\right)_{2}\right\}_{2}\right)_{2}\right]$ & 3 & benzene- $d_{6}$ & - & 45.8 & -3.44 \\
\hline$\left[\mathrm{Ba}\left\{\mu_{2}-\mathrm{N}\left(\mathrm{SiMe}_{3}\right)_{2}\right\}\left(\mathrm{OB}\left\{\mathrm{CH}\left(\mathrm{SiMe}_{3}\right)_{2}\right\}_{2}\right)\right]_{2}$ & 42 & benzene- $d_{6}$ & - & 43.7 & -3.47 \\
\hline$\left[\mathrm{Ba}\left\{\mu_{2}-\mathrm{OB}(\text { Tripp })_{2}\right\}\left\{\mathrm{OB}(\text { Tripp })_{2}\right\}\right]_{2}$ & $\mathbf{5}_{2}$ & thf- $\mathrm{d}_{8}$ & - & 47.1 & - \\
\hline$\left[\mathrm{Ba}\left\{\mu_{2}-\mathrm{OB}(\text { Fmes })_{2}\right\}\left\{\mathrm{OB}(\text { Fmes })_{2}\right\}\right]_{2}$ & $6_{2}$ & thf- $\mathrm{d}_{8}$ & $\begin{array}{l}-56.58 \\
-63.98\end{array}$ & 34.1 & - \\
\hline$\left[\mathrm{Ba}\left\{\mu_{2}-\mathrm{OB}(\mathrm{Tripp})_{2}\right\}\left\{\mathrm{N}\left(\mathrm{SiMe}_{3}\right)_{2}\right\}\right]_{2}$ & 72 & benzene- $d_{6}$ & - & 47.5 & -18.57 \\
\hline$\left[\mathrm{Ba}\left\{\mu_{2}-\mathrm{OSi}\left(\mathrm{SiMe}_{3}\right)_{3}\right\}\left(\mathrm{OB}\left\{\mathrm{CH}\left(\mathrm{SiMe}_{3}\right)_{2}\right\}_{2}\right)\right]_{2}$ & $\mathbf{8}_{2}$ & benzene- $d_{6}$ & - & 43.7 & $\begin{array}{l}-3.38 \\
-19.86 \\
-27.84\end{array}$ \\
\hline$\left[\mathrm{Ba}\left\{\mu_{2}-\mathrm{OB}(\mathrm{Tripp})_{2}\right\}\left\{\mathrm{OSi}\left(\mathrm{SiMe}_{3}\right)_{3}\right\}\right]_{2}$ & 92 & thf- $\mathrm{d}_{8}$ & - & not detected & $\begin{array}{l}-20.67 \\
-36.67\end{array}$ \\
\hline$\left[\mathrm{Ba}\left\{\mu_{2}-\mathrm{O}\left(2,6-\mathrm{Ph}_{2}-\mathrm{C}_{6} \mathrm{H}_{3}\right)\right\}\left\{\mathrm{OSi}\left(\mathrm{SiMe}_{3}\right)_{3}\right\}\right]_{2}$ & $10_{2}$ & thf- $\mathrm{d}_{8}$ & - & - & not detected \\
\hline
\end{tabular}

The molecular solid-state structure of $\left[\mathrm{Ba}\left\{\mu_{2}-\mathrm{OB}(\mathrm{Tripp})_{2}\right\}\left\{\mathrm{N}\left(\mathrm{SiMe}_{3}\right)_{2}\right\}\right]_{2}\left(\mathbf{7}_{\mathbf{2}}\right)$ shows the complex to be a centro-symmetric boryloxide-bridged dimer (Figure 4). Each barium is three-coordinate, with a 
distorted trigonal pyramidal environment $\left(\Sigma_{\theta}(\mathrm{Ba} 1)=325.97(8)^{\circ}\right)$ that reflects an $\eta^{1}$-interaction with the ipso $\mathrm{C}$-atom $(\mathrm{Ba} 1-\mathrm{C} 41=3.1380(18) \AA$; the other $\mathrm{Ba} 1-\mathrm{C}(\pi)$ interatomic distances are 3.497(2) $\AA$ or greater) in a neighbouring Tripp fragment. The Ba-O distances in $7_{2}$ (2.5932(13)-2.6789(13) $\AA$ ) are in the range of those in other related complexes having boryloxides in bridging positions, e.g. $\mathbf{5}_{\mathbf{2}}$ and $\mathbf{6}_{\mathbf{2}}$. The O21-B22-C41 angle involving the carbon atom (C41) that interacts with $\mathrm{Ba} 1$ is somewhat narrower that the O21-B22-C23 with the non-interacting C atom, 119.07(17) ${ }^{\circ}$ and $125.04(18)^{\circ}$, respectively. It must be noted that by contrast with $\mathbf{4}_{2}$ where the amides bridge the two metal atoms, in $\mathbf{7}_{\mathbf{2}}$ they occupy terminal positions. Hence, the nature of the boron-bound alkyl/aryl groups clearly affects the $\pi$-donating character of the oxygen atom in different boryloxides.

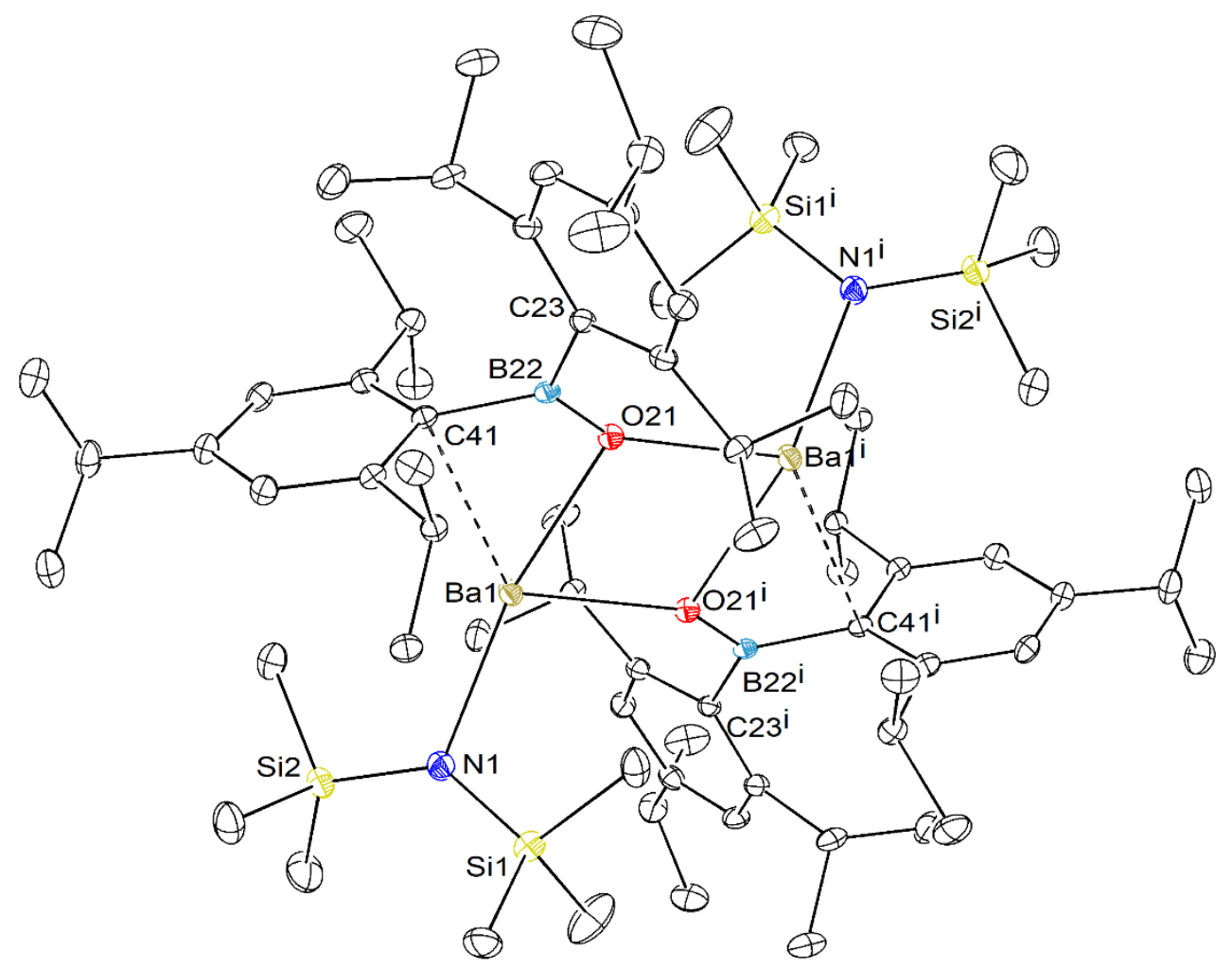

Figure 4. ORTEP view of the molecular structure of $\left[\mathrm{Ba}\left\{\mu_{2}-\mathrm{OB}(\mathrm{Tripp})_{2}\right\}\left\{\mathrm{N}\left(\mathrm{SiMe}_{3}\right)_{2}\right\}\right]_{2}\left(\mathbf{7}_{\mathbf{2}}\right)$. H atoms omitted for clarity. Ellipsoids at the $30 \%$ probability level. Selected interatomic distances $(\AA)$ and angles $\left({ }^{\circ}\right)$ : Ba1-N1 = 2.5512(17), Ba1-O21 = 2.6789(13), Ba1-O21 ${ }^{\mathrm{i}}=2.5932(13), \mathrm{Ba} 1-\mathrm{C} 41=3.1380(18), \mathrm{O} 21-\mathrm{B} 22=1.334(2), \mathrm{N} 1-\mathrm{Si} 1$ $=1.6825(18), \mathrm{N} 1-\mathrm{Si} 2=1.6803(19) ; \mathrm{N} 1-\mathrm{Ba} 1-\mathrm{O} 21=140.52(5), \mathrm{N} 1-\mathrm{Ba} 1-\mathrm{O} 21^{\mathrm{i}}=109.53(5), \mathrm{O} 21-\mathrm{Ba} 1-\mathrm{O} 21^{\mathrm{i}}=$ 75.92(4). B22-O21-Ba1 = 105.69(11), B22-O21-Ba1 ${ }^{\mathrm{i}}=149.24(12), \mathrm{Ba} 1-\mathrm{O} 21-\mathrm{Ba} 1^{\mathrm{i}}=104.08(4), \mathrm{O} 21-\mathrm{B} 22-\mathrm{C} 23=$ 125.04(18), O21-B22-C41 = 119.07(17). Symmetry transformations: i, -x, -y, -z, T = [2, 0, 0].

$\left[\mathrm{Ba}\left\{\mu_{2}-\mathrm{OSi}\left(\mathrm{SiMe}_{3}\right)_{3}\right\}\left(\mathrm{OB}\left\{\mathrm{CH}\left(\mathrm{SiMe}_{3}\right)_{2}\right\}_{2}\right)\right]_{2}\left(\mathbf{8}_{2}\right)$ forms a $C_{\mathrm{s}}$-symmetric dimer bridged by the two siloxides (Figure 5), with a symmetry plane going through the barium and two terminal oxygen atoms. The asymmetric unit contains three independent and similar molecules, only one of which is discussed here. Unlike in for instance $\mathbf{5}_{\mathbf{2}}$ and $\mathbf{7}_{\mathbf{2}}$, the $\mathrm{Ba}_{2} \mathrm{O}_{2}$ core is not planar, as $\mathrm{Ba} 2$ protrudes out of the best plane defined by $\mathrm{Ba} 1, \mathrm{O} 21$ and $\mathrm{O} 51$ presumably due to the steric constraints imposed by the very bulky ligands. Each barium is three-coordinate, but the geometry about $\mathrm{Ba} 1$ and $\mathrm{Ba} 2$ is very different due to 
the fact that one of the terminal boryloxides (at $\mathrm{Ba} 2$ ) is tilted towards the core of the dimer, while the other (at Ba1) is pointing away from it. Hence, Ba1 rests in a trigonal planar geometry $\left(\Sigma_{\theta}(\mathrm{Ba} 1)=\right.$ $\left.357.54(19)^{\circ}\right)$, while the geometry around $\mathrm{Ba} 2$ is pyramidalised $\left(\Sigma_{\theta}(\mathrm{Ba} 2)=314.62(19)^{\circ}\right)$. Overall, the geometrical arrangement in $\mathbf{8}_{\mathbf{2}}$ appears to be intermediate between those in $\mathbf{2}_{\mathbf{2}}$ (a $C_{\mathrm{s}}$-symmetric dimer with 3 bridging siloxides and a single terminal one, ${ }^{[29]}$ see Figure 1) and, for instance, the $\mathrm{C}_{\mathrm{i}}$-symmetric 52. The Ba-O interatomic distances are unremarkable and compare well with those in the barium boryloxides and siloxides described previously here and elsewhere. ${ }^{[27-29]}$ Complex $\mathbf{8}_{2}$ exhibits four short Ba-H interatomic distances in the range 2.493(6)-2.777(7) $\AA$ (not depicted) that may indicate the presence of $\mathrm{Ba} \cdots \mathrm{H}-\mathrm{C}$ anagostic interactions contributing to its stability; however, no spectroscopic evidence for the existence of such interactions could be detected.

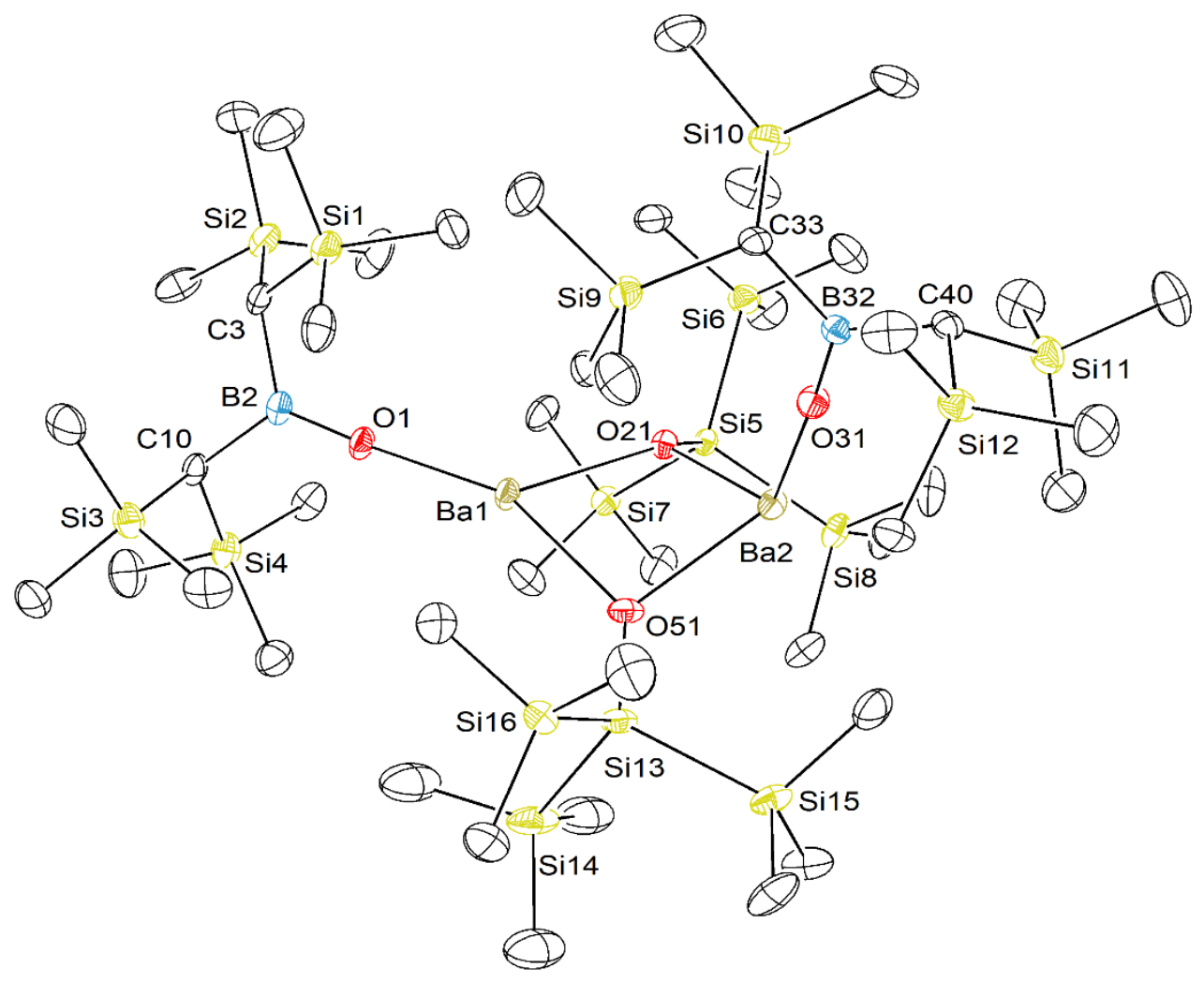

Figure 5. ORTEP view of the molecular structure of $\left[\mathrm{Ba}\left\{\mu_{2}-\mathrm{OSi}\left(\mathrm{SiMe}_{3}\right)_{3}\right\}\left(\mathrm{OB}\left\{\mathrm{CH}\left(\mathrm{SiMe}_{3}\right)_{2}\right\}_{2}\right)\right]_{2}\left(\mathbf{8}_{2}\right)$. Only one of the three independent but very similar molecules in the asymmetric unit depicted. $\mathrm{H}$ atoms omitted for clarity. Ellipsoids at the $30 \%$ probability level. Selected interatomic distances $(\AA)$ and angles $\left({ }^{\circ}\right)$ : Ba1-O1 = 2.431(3), Ba1$\mathrm{O} 21=2.549(3), \mathrm{Ba} 1-\mathrm{O} 51=2.635(3), \mathrm{Ba} 2-\mathrm{O} 5=2.551(3), \mathrm{Ba} 2-\mathrm{O} 31=2.386(3), \mathrm{Ba} 2-\mathrm{O} 21=2.584(3), \mathrm{O} 1-\mathrm{B} 2=$ 1.331(6), O31-B32 = 1.326(6); O1-Ba1-O21 = 124.71(11), O1-Ba1-O51 = 156.57(11), O21-Ba1-O51 = 76.26(11), $\mathrm{O} 21-\mathrm{Ba} 2-\mathrm{O} 31=120.37(11), \mathrm{O} 21-\mathrm{Ba} 2-\mathrm{O} 51=77.14(10), \mathrm{O} 31-\mathrm{Ba} 2-\mathrm{O} 51=117.11(12), \mathrm{B} 2-\mathrm{O} 1-\mathrm{Ba} 1=164.8(3)$, B32-O31-Ba2 = 170.20(4), O1-B2-C3 = 120.5(5), O1-B2-C10 = 122.6(5), C3-B2-C10 = 116.8(4), O31-B32-C33 $=120.3(4), \mathrm{O} 31-\mathrm{B} 32-\mathrm{C} 40=120.3(4), \mathrm{C} 33-\mathrm{B} 32-\mathrm{C} 40=119.3(4)$.

$\left[\mathrm{Ba}\left\{\mu_{2}-\mathrm{OB}(\mathrm{Tripp})_{2}\right\}\left\{\mathrm{OSi}\left(\mathrm{SiMe}_{3}\right)_{3}\right\}\right]_{2}\left(\mathbf{9}_{2}\right)$ forms a centro-symmetric dimer bridged by $\mathrm{O}_{\text {boryloxide }}$ atoms, with a planar $\mathrm{Ba}_{2} \mathrm{O}_{2}$ rhomboidal core and terminal siloxides (Figure 6). The geometry around 
each barium atom is trigonal pyramidal $\left(\Sigma_{\theta}(\mathrm{Ba} 1)=314.9(6)^{\circ}\right)$, with deviation from the expected trigonal planar arrangement due to the presence of $\mathrm{Ba} \cdots \mathrm{C}(\pi) \eta^{3}$-interactions with flanking aromatic groups. The corresponding Ba-C interatomic distances are in the range 3.074(10)-3.265(10) $\AA$. Note that the Ba1$\mathrm{O} 1$-Si1 angle of $172.0(6)^{\circ}$ is particularly wide, which suggests substantial sp-hybridisation at $\mathrm{O} 1$ due to the participation of the lone pairs of electrons to the formation of the O1-Ba1 and O1-Si1 bonds. This angle and the Ba1-O1 bond length (2.377(10) $\AA$ ) match the pertaining ones in other dimeric complexes having the bulky siloxide $\mathrm{OSi}\left(\mathrm{SiMe}_{3}\right)_{3}$ in terminal positions, e.g. as in $\mathbf{1}_{2}\left(2.414(7) \AA\right.$ and $\left.173.50(5)^{\circ}\right)$.

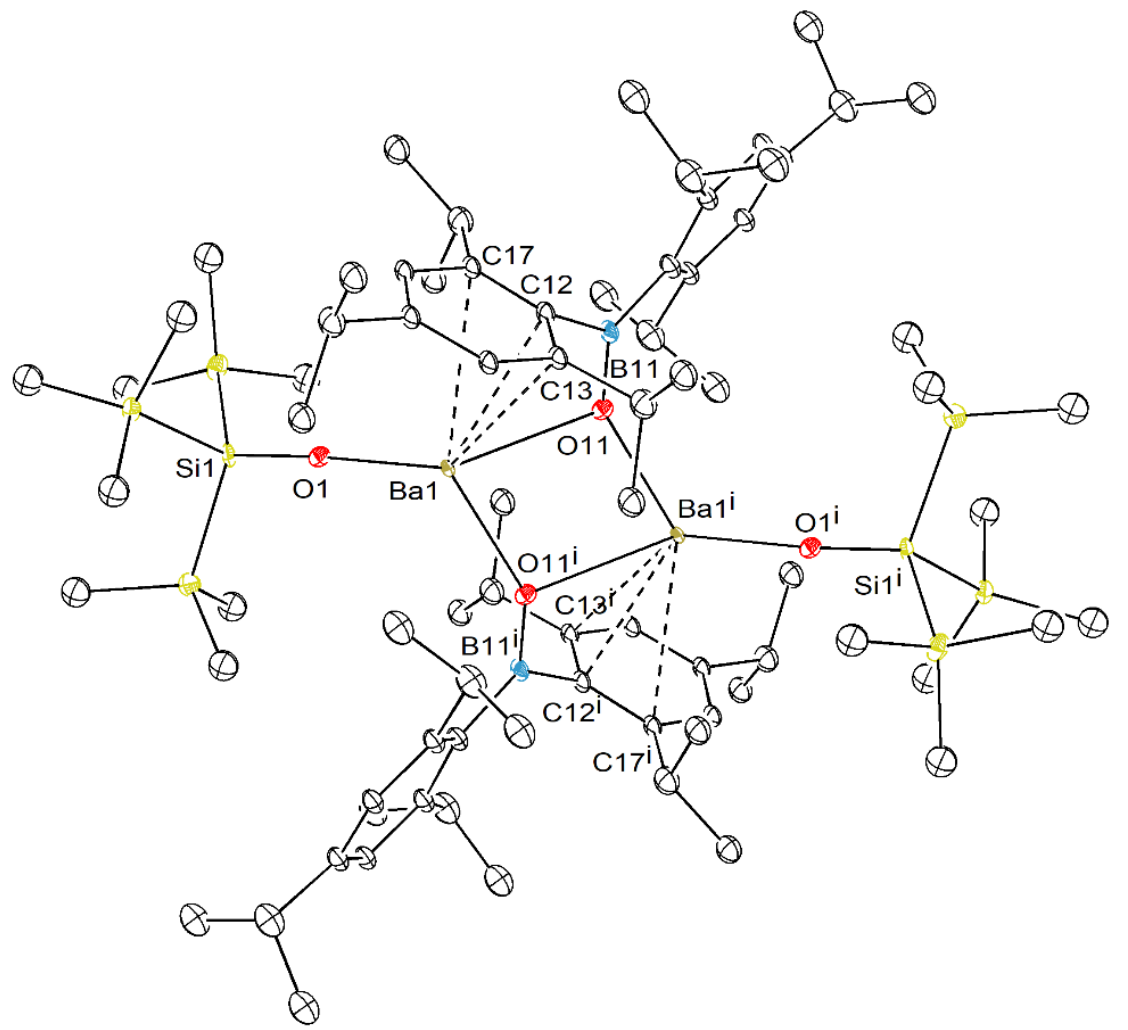

Figure 6. ORTEP view of the molecular structure of $\left[\mathrm{Ba}\left\{\mu_{2}-\mathrm{OB}(\mathrm{Tripp})_{2}\right\}\left\{\mathrm{OSi}\left(\mathrm{SiMe}_{3}\right)_{3}\right\}\right]_{2}\left(\mathbf{9}_{2}\right)$. H atoms omitted for clarity. Ellipsoids at the $30 \%$ probability level. Selected interatomic distances $(\AA)$ and angles $\left({ }^{\circ}\right)$ : Ba1-O1 = 2.377(10), Ba1-O11 = 2.778(10), Ba1-O11 ${ }^{\mathrm{i}}=2.560(10), \mathrm{Ba} 1-\mathrm{C} 12=3.074(10), \mathrm{Ba} 1-\mathrm{C} 13=3.198(10), \mathrm{Ba} 1-\mathrm{C} 17=$ 3.265(10); O1-Ba1-O11 = 130.0(3), O1-Ba1-O11 ${ }^{\mathrm{i}}=109.9(3), \mathrm{O} 11-\mathrm{Ba} 1-\mathrm{O} 11^{\mathrm{i}}=75.0(4), \mathrm{Si} 1-\mathrm{O} 1-\mathrm{Ba} 1=172.0(6)$. Symmetry transformations used to generate equivalent atoms: $\mathrm{i},-\mathrm{x},-\mathrm{y},-\mathrm{z}, \mathrm{T}=[1,0,0]$.

The molecular structure of $\left[\mathrm{Ba}\left\{\mu_{2}-\mathrm{O}\left(2,6-\mathrm{Ph}_{2}-\mathrm{C}_{6} \mathrm{H}_{3}\right)\right\}\left\{\mathrm{OSi}\left(\mathrm{SiMe}_{3}\right)_{3}\right\}\right]_{2}\left(\mathbf{1 0}_{2}\right)$ depicted in Figure 7 shows it to be a centro-symmetric dimer bridged through the $\mathrm{O}_{\text {phenoxide }}$ atoms which, like $\mathbf{9}_{2}$, has two siloxides in terminal positions. The main structural features of these two complexes are surprisingly similar due to the presence of flanking aromatic moieties in the bridging groups. Hence, in $\mathbf{1 0}_{2}$, the bariums atoms are also in a three-coordinate trigonal pyramidal geometry $\left(\Sigma_{\theta}(\mathrm{Ba} 1)=297.73(8)^{\circ}\right)$ imposed by the additional presence of multiple secondary Ba $\cdots C(\pi) \eta^{3}$-interactions (within 3.199(2)$3.321(2) \AA$ ) with each of the four phenyl substituents in ortho positions. Similar $\mathrm{Ba} \cdots \mathrm{C}(\pi)$ interactions have already been observed, e.g. in the structurally unusual homoleptic Ba-bis(phenoxide) $\left[\mathrm{Ba}_{2}\left\{\mu_{2^{-}}\right.\right.$ $\mathrm{O}\left(2,6-\mathrm{Ph}_{2}-\mathrm{C}_{6} \mathrm{H}_{3}\right\}_{3}\left\{\mu_{2}-\mathrm{O}\left(2,6-\mathrm{Ph}_{2}-\mathrm{C}_{6} \mathrm{H}_{3}\right\}\right] .{ }^{[46]}$ The values of the Ba1-O1 interatomic distance and Ba1-O1- 
Sil angle (2.3564(14) $\AA$ and 166.68(9) ${ }^{\circ}$, respectively) are commensurate with those in $\mathbf{9}_{2}$ and $\mathbf{1}_{2}$ (see above). The Ba1-O23 and Ba1-O23 ${ }^{\mathrm{i}}$ bond lengths from Ba to bridging $\mathrm{O}_{\text {phenoxide }}$ atoms (2.6728(14)2.7152(14) $\AA$ ) are similar to those measured in other barium phenoxides. ${ }^{[64,65]}$

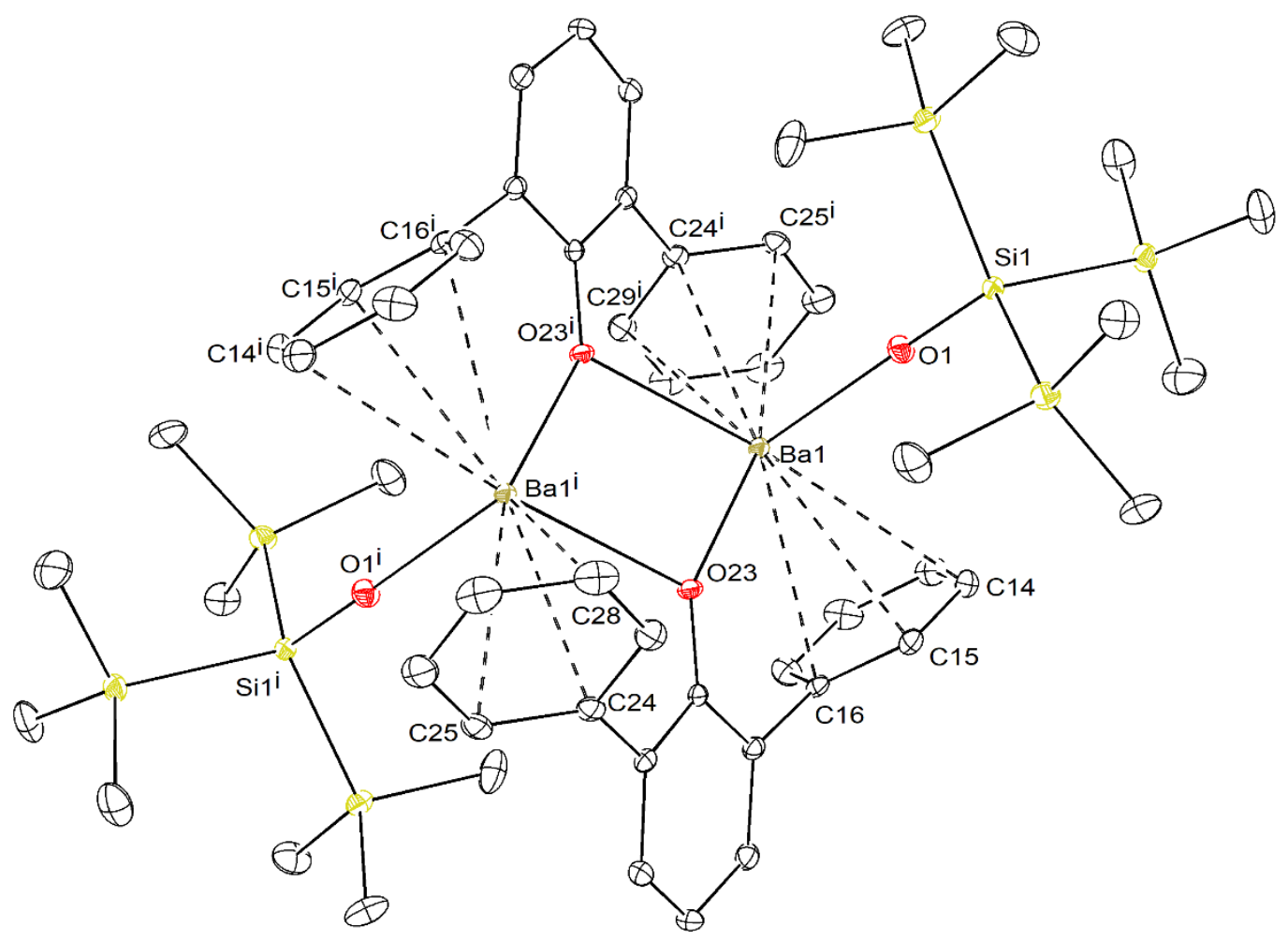

Figure 7. ORTEP view of the molecular structure of $\left[\mathrm{Ba}\left\{\mu_{2}-\mathrm{O}\left(2,6-\mathrm{Ph}_{2}-\mathrm{C}_{6} \mathrm{H}_{3}\right)\right\}\left\{\mathrm{OSi}\left(\mathrm{SiMe}_{3}\right)_{3}\right\}\right]_{2}\left(\mathbf{1 0}_{2}\right)$. $\mathrm{H}$ atoms omitted for clarity. Ellipsoids at the $30 \%$ probability level. Selected interatomic distances $(\AA)$ and angles $\left({ }^{\circ}\right)$ : Ba1$\mathrm{O} 1=2.3564(14), \mathrm{Ba} 1-\mathrm{O} 23=2.6728(14), \mathrm{Ba} 1-\mathrm{O} 23^{\mathrm{i}}=2.7152(14), \mathrm{Ba}-\mathrm{C} 14=3.321(2), \mathrm{Ba} 1-\mathrm{C} 15=3.199(2), \mathrm{Ba} 1-$ $\mathrm{C} 16=3.2031(19), \mathrm{Ba} 1-\mathrm{C} 24^{\mathrm{i}}=3.120(2), \mathrm{Ba} 1-\mathrm{C} 25^{\mathrm{i}}=3.252(2), \mathrm{Ba} 1-\mathrm{C} 29^{\mathrm{i}}=3.273(2) ; \mathrm{O} 1-\mathrm{Ba} 1-\mathrm{O} 23=111.75(5)$, $\mathrm{O} 1-\mathrm{Ba} 1-\mathrm{O} 23^{\mathrm{i}}=107.11(5), \mathrm{O} 23-\mathrm{Ba} 1-\mathrm{O} 23^{\mathrm{i}}=78.87(4), \mathrm{Ba} 1-\mathrm{O} 1-\mathrm{Si} 1=166.68(9)$. Symmetry transformations used to generate equivalent atoms: $\mathrm{i},-\mathrm{x},-\mathrm{y},-\mathrm{z}, \mathrm{T}=[1,0,0]$.

\section{Summary of crystallographic data for barium complexes}

In combination with our earlier contributions, ${ }^{[27-29]}$ the results disclosed herein indicate that a range of soluble barium boryloxides, siloxides and phenoxides $\mathbf{1}_{\mathbf{2}}-\mathbf{1 0}_{\mathbf{2}}$ are synthetically available. They feature a diversity of structural patterns in the molecular solid-state, with the main ones (nuclearity, structural type, coordination number and presence of non-covalent interactions) highlighted in Table 2. Most of these compounds exist as dimeric species in the solid state, where two different bridging modes for the $\mathrm{Ba}_{2} \mathrm{O}_{4}$ core have been identified: a classical and largely prevailing one with two bridging and two terminal ligands, and a minor one, with three bridging groups and a single terminal ligand as in $\mathbf{1}_{\mathbf{2}}$ and its thf adduct 1 12.thf. ${ }^{[29]}$ This latter, unusual arrangement is reminiscent of that found in the molecular structure of the alkoxide $\left[\mathrm{Ba}_{2}\left(\mu_{2}-\mathrm{OCPh}_{3}\right)_{3}\left(\mathrm{OCPh}_{3}\right)(\text { thf })_{3}\right]{ }^{[42]}$ Other than this complex, there are very few examples of discrete homometallic barium alkoxides indexed in the CCDC database ${ }^{[66]}$ for simple alkoxo groups, ${ }^{[67]}$ even though the structures of several fluoroalkoxides, as in 
$\left[\mathrm{Ba}\left\{\mathrm{OC}\left(\mathrm{CF}_{3}\right)_{3}\right\}_{2}(\mathrm{dme})_{3}\right],{ }^{[42]}$ and those of heterobimetallic species, e.g. $\left[\mathrm{Zr}_{2} \mathrm{Ba}\left(\mu_{2}-\mathrm{O}^{\mathrm{t}} \mathrm{Bu}\right)_{6}\left(\mathrm{O}^{\mathrm{t}} \mathrm{Bu}\right)_{4}\right]{ }^{[68]}$ have been described. Taken collectively, these data also point to the importance of $\mathrm{Ba} \cdots \mathrm{F}, \mathrm{Ba} \cdots \mathrm{C}(\pi)$ and even $\mathrm{Ba} \cdots \mathrm{H}-\mathrm{C}$ secondary interactions towards the stability of these complexes; these non-covalent interactions are broken upon coordination of Lewis bases, as in the solvated $\mathbf{1}_{2}$.thf, 3.(thf) $)_{2}$ and $\mathbf{6}_{2}$.thf.

Table 2. Summary of solid-state structural data for barium siloxides, boryloxides and phenoxides $\mathbf{1}_{2}-\mathbf{1 0}_{2}$.

\begin{tabular}{|c|c|c|c|c|c|}
\hline \multirow{2}{*}{\multicolumn{6}{|c|}{ 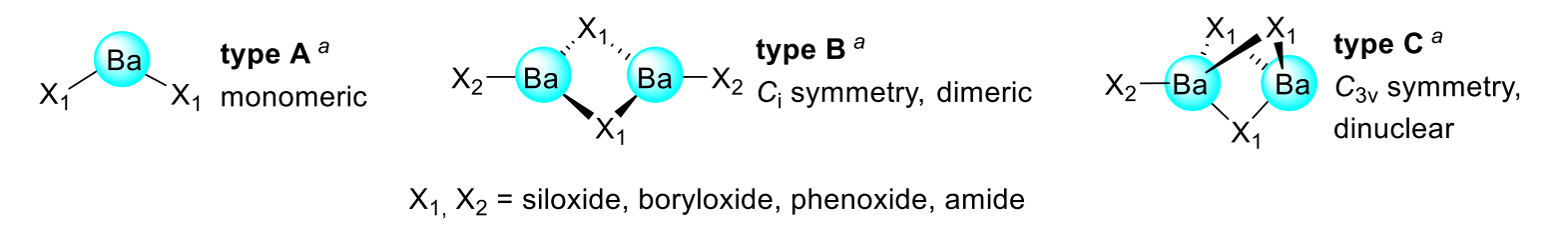 }} \\
\hline & & & & & \\
\hline \multicolumn{2}{|c|}{ Complex } & $\begin{array}{l}\text { structural } \\
\text { motif }\end{array}$ & $\begin{array}{l}\text { coordination } \\
\text { number }\end{array}$ & $\begin{array}{l}\text { secondary } \\
\text { interactions }\end{array}$ & ref. \\
\hline$\left[\mathrm{Ba}_{2}\left\{\mu_{2}-\mathrm{OSi}\left(\mathrm{SiMe}_{3}\right)_{3}\right\}_{3}\left\{\mathrm{OSi}\left(\mathrm{SiMe}_{3}\right)_{3}\right\}\right]$ & $1 \mathbf{1}_{2}$ & $\mathrm{C}$ & $3 \& 4$ & $\mathrm{Ba} \cdots \mathrm{H}-\mathrm{C}$ & [29] \\
\hline$\left[\mathrm{Ba}_{2}\left\{\mu_{2}-\mathrm{OSi}\left(\mathrm{SiMe}_{3}\right)_{3}\right\}_{3}\left\{\mathrm{OSi}\left(\mathrm{SiMe}_{3}\right)_{3}\right\}\right.$.thf $]$ & 12.thf & $\mathrm{C}$ & $4 \& 4$ & - & [29] \\
\hline$\left[\mathrm{Ba}\left\{\mu_{2}-\mathrm{OSi}\left(\mathrm{SiMe}_{3}\right)_{3}\right\}\left\{\mathrm{N}\left(\mathrm{SiMe}_{3}\right)_{2}\right\}\right]_{2}$ & 22 & B & 3 & - & [29] \\
\hline$\left[\mathrm{Ba}\left(\mathrm{OB}\left\{\mathrm{CH}\left(\mathrm{SiMe}_{3}\right)_{2}\right\}_{2}\right)_{2}\right]$ & 3 & A & 2 & $\mathrm{Ba} \cdots \mathrm{H}-\mathrm{C}$ & [27] \\
\hline$\left[\mathrm{Ba}\left(\mathrm{OB}\left\{\mathrm{CH}\left(\mathrm{SiMe}_{3}\right)_{2}\right\}_{2}\right)_{2}\right.$.toluene $]$ & 3.tol & A & 2 & $\mathrm{Ba} \cdots \mathrm{C}(\pi)$ & [28] \\
\hline$\left[\mathrm{Ba}\left(\mathrm{OB}\left\{\mathrm{CH}\left(\mathrm{SiMe}_{3}\right)_{2}\right\}_{2}\right)_{2} .(\text { thf })_{2}\right]$ & 3. $(\text { thf })_{2}$ & A & 4 & - & [27] \\
\hline$\left[\mathrm{Ba}\left\{\mu_{2}-\mathrm{N}\left(\mathrm{SiMe}_{3}\right)_{2}\right\}\left(\mathrm{OB}\left\{\mathrm{CH}\left(\mathrm{SiMe}_{3}\right)_{2}\right\}_{2}\right)\right]_{2}$ & $4_{2}$ & B & 3 & - & $b$ \\
\hline$\left[\mathrm{Ba}\left\{\mu_{2}-\mathrm{OB}(\text { Tripp })_{2}\right\}\left\{\mathrm{OB}(\text { Tripp })_{2}\right\}\right]_{2}$ & $\mathbf{5}_{2}$ & B & 3 & $\mathrm{Ba} \cdots \mathrm{C}(\pi)$ & $b$ \\
\hline$\left[\mathrm{Ba}\left\{\mu_{2}-\mathrm{OB}(\mathrm{Fmes})_{2}\right\}\left\{\mathrm{OB}(\mathrm{Fmes})_{2}\right\}\right]_{2}$ & $6_{2}$ & $\mathrm{~B}^{c}$ & 3 & $\mathrm{Ba} \cdots \mathrm{F}$ & $b$ \\
\hline$\left[\mathrm{Ba}\left\{\mu_{2}-\mathrm{OB}(\mathrm{Fmes})_{2}\right\}\left\{\mathrm{OB}(\text { Fmes })_{2}\right\} \cdot \text { thf }\right]_{2}$ & 62.thf & B & 4 & - & $b$ \\
\hline$\left[\mathrm{Ba}\left\{\mu_{2}-\mathrm{OB}(\text { Tripp })_{2}\right\}\left\{\mathrm{N}\left(\mathrm{SiMe}_{3}\right)_{2}\right\}\right]_{2}$ & 72 & B & 3 & $\mathrm{Ba} \cdots \mathrm{C}(\pi)$ & $b$ \\
\hline$\left[\mathrm{Ba}\left\{\mu_{2}-\mathrm{OSi}\left(\mathrm{SiMe}_{3}\right)_{3}\right\}\left(\mathrm{OB}\left\{\mathrm{CH}\left(\mathrm{SiMe}_{3}\right)_{2}\right\}_{2}\right)\right]_{2}$ & $8_{2}$ & $\mathrm{~B}^{d}$ & 3 & $\mathrm{Ba} \cdots \mathrm{H}-\mathrm{C}$ & $b$ \\
\hline$\left[\mathrm{Ba}\left\{\mu_{2}-\mathrm{OB}(\mathrm{Tripp})_{2}\right\}\left\{\mathrm{OSi}\left(\mathrm{SiMe}_{3}\right)_{3}\right\}\right]_{2}$ & $9_{2}$ & B & 3 & $\mathrm{Ba} \cdots \mathrm{C}(\pi)$ & $b$ \\
\hline$\left[\mathrm{Ba}\left\{\mu_{2}-\mathrm{O}\left(2,6-\mathrm{Ph}_{2}-\mathrm{C}_{6} \mathrm{H}_{3}\right)\right\}\left\{\mathrm{OSi}\left(\mathrm{SiMe}_{3}\right)_{3}\right\}\right]_{2}$ & $10_{2}$ & B & 3 & $\mathrm{Ba} \cdots \mathrm{C}(\pi)$ & $b$ \\
\hline
\end{tabular}

Examination of the data for the six heteroleptic complexes obtained so far, namely $\mathbf{2}_{\mathbf{2}}, \mathbf{4}_{\mathbf{2}}$ and $\mathbf{7}_{\mathbf{2}}$ $\mathbf{1 0}_{2}$, indicate that the relative position (bridging vs terminal) of a given ligand in dimeric complexes changes with its identity. Hence, the propensity of a given anion to occupy the bridging position increases according to the empirical relationships displayed in Figure 8. No information can be provided about (Fmes) ${ }_{2} \mathrm{BO}^{-}$, as we failed to obtain structurally characterised heteroleptic complexes with this ligand. The boryloxide $\left\{\left(\mathrm{Me}_{3} \mathrm{Si}\right)_{2} \mathrm{CH}\right\}_{2} \mathrm{BO}^{-}$seems to be unable to generate dinuclear species, supposedly 
owing to its considerable steric bulk. Besides, we have so far not succeeded in our attempts to discriminate between (Tripp) ${ }_{2} \mathrm{BO}^{-}$and $2,6-\mathrm{Ph}_{2}-\mathrm{C}_{6} \mathrm{H}_{3}-\mathrm{O}^{-}$. The empirical classification provided in Figure 8 is established on the sole basis of crystallographic data. It most probably is the expression of a composite of different properties for these ligands, such as (i) steric features, (ii) electronic density and overall $\sigma$ - and $\pi$-donor capability of the negatively charged atom $\left(\mathrm{O}^{-}\right.$or $\left.\mathrm{N}^{-}\right)$, and (iii) the ability to generate $\mathrm{Ba} \cdots \mathrm{F}, \mathrm{Ba} \cdots \mathrm{H}-\mathrm{C}$ or $\mathrm{Ba} \cdots \mathrm{C}(\pi)$ secondary interactions. The particularly large size of the $\mathrm{Ba}^{2+}$ cation $\left(r_{\text {ionic }}=1.35 \AA\right.$ ), and the resulting ability to accommodate bulky ligands and additional secondary interactions, must also be a contributing factor. Although it seems reasonable to hypothesise so, it is unclear at this stage to which extent the relationships displayed in Figure 8 can be extrapolated to the comparatively smaller calcium and strontium $\left(r_{\text {ionic }}=1.00\right.$ and $1.18 \AA$ ).
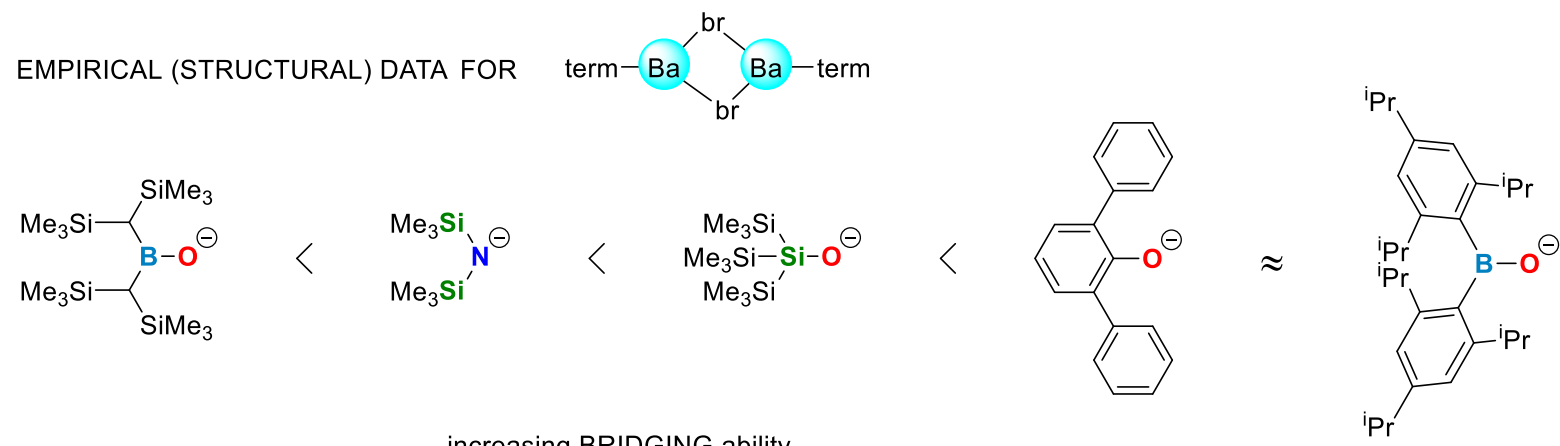

increasing BRIDGING ability

Figure 8. Relative bridging ability of O-based monoanionic ligands established from the structural data for the dinuclear heteroleptic barium complexes $\mathbf{2}_{\mathbf{2}}, \mathbf{4}_{\mathbf{2}}$ and $\mathbf{7}_{\mathbf{2}}-\mathbf{1 0} \mathbf{2}_{2} . \mathrm{Br}=$ bridging and term $=$ terminal positions.

\section{Comparison between alkaline earths.}

The heteroleptic complexes $\left[\mathrm{Ae}\left\{\mu_{2}-\mathrm{N}\left(\mathrm{SiMe}_{3}\right)_{2}\right\}\left(\mathrm{OB}\left\{\mathrm{CH}\left(\mathrm{SiMe}_{3}\right)_{2}\right\}_{2}\right)\right]_{2}\left(\mathrm{Ae}=\mathrm{Mg}, \mathbf{1 1}_{2} ; \mathrm{Ca}, \mathbf{1 2}_{2} ; \mathrm{Sr}, \mathbf{1 3}_{2}\right)$ were prepared in $53-84 \%$ yields by reaction of $\left[\mathrm{Ae}\left\{\mathrm{N}\left(\mathrm{SiMe}_{3}\right)_{2}\right\}_{2}\right]_{2}$ with $\left\{\left(\mathrm{Me}_{3} \mathrm{Si}\right)_{2} \mathrm{CH}\right\}_{2} \mathrm{BOH}$. In conjunction with the barium complex $\left[\mathrm{Ba}\left\{\mu_{2}-\mathrm{N}\left(\mathrm{SiMe}_{3}\right)_{2}\right\}\left(\mathrm{OB}\left\{\mathrm{CH}\left(\mathrm{SiMe}_{3}\right)_{2}\right\}_{2}\right)\right]_{2}\left(\mathbf{4}_{2}\right),{ }^{[27]}$ they afford a complete series of homologous heteroleptic dimers. The molecular structures of the three new complexes were determined by XRD analysis performed on single crystals. Like $\mathbf{4}_{2}$, they all form dimer bridged by the amido groups, while the boryloxides are located in terminal positions. Although not identical (vide infra), the structural arrangement is similar across the four complexes, hence only the strontium complex $\mathbf{1 3}_{\mathbf{2}}$ is detailed here; the ORTEP representations $\mathbf{1 1}_{\mathbf{2}}$ and $\mathbf{1 2}_{\mathbf{2}}$ can be found in the Supporting Information (Figures S47-S48) with a list of representative metric parameters.

Complex 132 forms a $C_{1}$-symmetric dimer with a flat, rhomboidal $\mathrm{Sr}_{2} \mathrm{~N}_{2}$ core (Figure 9). The geometry about the two $\mathrm{Sr}$ atoms differs slightly. The two B1-O1-Sr1 and B2-O2-Sr2 angles close to perfectly linear $\left(178.90(16)^{\circ}\right.$ and $\left.173.51(19)^{\circ}\right)$ suggest the participation of the lone pairs at $\mathrm{O}$ to the formation of $s p$-hybridised orbitals, and all six B1-O1-Sr1-B2-O2-Sr2 atoms are nearly aligned. The geometry about each strontium is trigonal planar $\left(\Sigma_{\theta}(\operatorname{Sr} 1)=359.99(11)^{\circ} ; \Sigma_{\theta}(\operatorname{Sr} 2)=359.79(11)^{\circ}\right)$. The bridging position of the two $\mathrm{N}\left(\mathrm{SiMe}_{3}\right)_{2}^{-}$ligands is unusual. To our knowledge, the sole other example 
of such heteroleptic dimer is $\left[\mathrm{Sr}\left\{\mu-\mathrm{N}\left(\mathrm{SiMe}_{3}\right)_{2}\right\}\left\{\mathrm{N}\left(\mathrm{C}_{6} \mathrm{~F}_{5}\right)_{2}\right\}\right]_{2},{ }^{[69]}$ where the $\mathrm{Sr}-\mathrm{N}_{\mathrm{br}}$ interatomic distances, in the range 2.598(2)- 2.634(2) $\AA$, match well those in $\mathbf{1 3}_{2}$ (2.601(2)-2.648(2) $\AA$ ). The two boron atoms are also in a perfect trigonal planar environment $\left(\Sigma_{\theta}(\mathrm{B} 1)=360.0(3)^{\circ} ; \Sigma_{\theta}(\mathrm{B} 2)=359.9(3)^{\circ}\right)$.

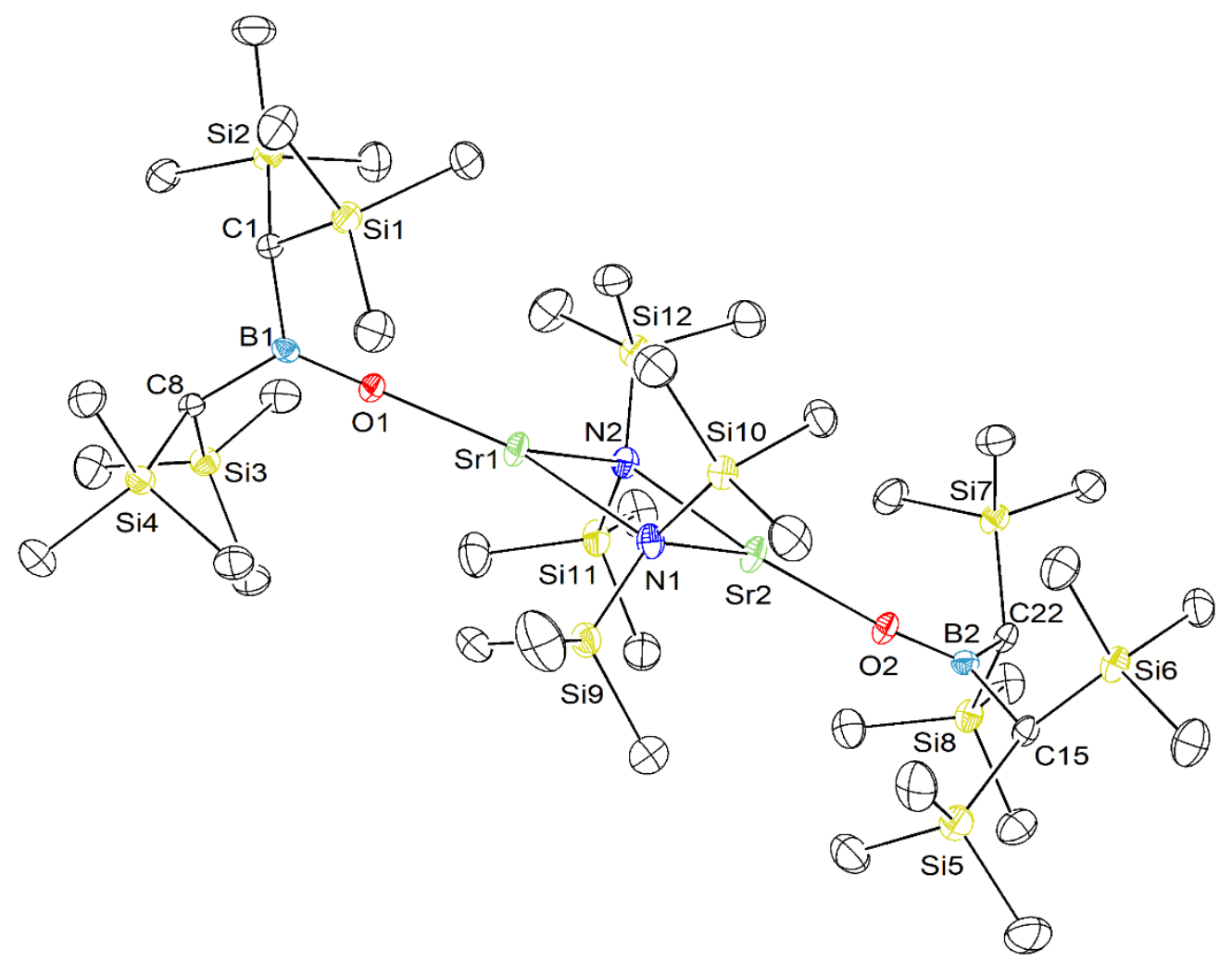

Figure 9. ORTEP view of the molecular structure of $\left[\mathrm{Sr}\left\{\mu_{2}-\mathrm{N}\left(\mathrm{SiMe}_{3}\right)_{2}\right\}\left(\mathrm{OB}\left\{\mathrm{CH}\left(\mathrm{SiMe}_{3}\right)_{2}\right\}_{2}\right)\right]_{2}\left(\mathbf{1 3}_{2}\right)$. $\mathrm{H}$ atoms omitted for clarity. Ellipsoids at the $50 \%$ probability level. Selected interatomic distances $(\AA)$ and angles $\left({ }^{\circ}\right)$ : $\mathrm{Sr} 1-$ $\mathrm{N} 1=2.648(2), \mathrm{Sr} 1-\mathrm{N} 2=2.634(2), \mathrm{Sr} 1-\mathrm{O} 1=2.2751(18), \mathrm{Sr} 2-\mathrm{N} 1=2.601(2), \mathrm{Sr} 2-\mathrm{N} 2=2.635(2), \mathrm{Sr} 2-\mathrm{O} 2=$ 2.2727(18), O1-B1 = 1.351(3), O2-B2 = 1.346(3); Sr1-N1-Sr2 = 95.19(7), Sr1-N2-Sr2 = 94.71(7), N1-Sr1-N2 = 84.59(7), N1-Sr1-O1 = 139.43(6), N2-Sr1-O1 = 135.97(7), N1-Sr2-N2 = 85.49(7), N1-Sr2-O2 = 132.46(7), N2$\mathrm{Sr} 2-\mathrm{O} 2=141.84(6), \mathrm{B} 1-\mathrm{O} 1-\mathrm{Sr} 1=178.90(16), \mathrm{B} 2-\mathrm{O} 2-\mathrm{Sr} 2=173.51(19), \mathrm{O} 1-\mathrm{B} 1-\mathrm{C} 1=121.8(2), \mathrm{O} 1-\mathrm{B} 1-\mathrm{C} 8=$ 121.6(2), C1-B1-C8 = 116.6(2), O2-B2-C15 = 121.8(2), O2-B2-C22 = 121.1(2), C15-B2-C22 = 117.0(2).

The main structural features are very similar across the three amide-bridged complexes $\mathbf{1 1}_{2}, \mathbf{1 2}_{\mathbf{2}}$ and $\mathbf{1 3} \mathbf{3}_{2}$ (all $C_{1}$-symmetrical, although the metric parameters is geometrical arrangements about the two metals atoms in both $\mathbf{1 1}_{2}$ and $\mathbf{1 2}_{2}$ are almost identical, resulting in a pseudo- $C_{2}$ symmetry), and they resemble those in the known barium congener $\mathbf{4}_{2}$. The most representative data are compiled in Table 3 . While the eight $\mathrm{B}, \mathrm{O}$, Met and $\mathrm{N}$ atoms are coplanar or very nearly so in $\mathbf{1 1}_{2}-\mathbf{1 3}_{\mathbf{2}}$ (see for instance the extremely short distances between the oxygen or boron atoms and the best average plane defined by the $\mathrm{Ae}_{2} \mathrm{~N}_{2}$ planar core in these complexes), the two O-atoms and two $\mathrm{B}$-atoms protrude out of the $\mathrm{Ba}_{2} \mathrm{~N}_{2}$ planar core in the $C_{\mathrm{i}}$-symmetric barium complex $\mathbf{4}_{2}$. This last compound is also the only one where the geometry about the metal atoms shows noticeable pyramidalisation $\left(\Sigma_{\theta}(\mathrm{Ba})=348.16(9)^{\circ}\right)$. The Ae-to$\mathrm{O}$ and $\mathrm{Ae}-\mathrm{to}-\mathrm{N}$ interatomic distances globally increase as expected on account of the differences between the ionic radii of the $\mathrm{Mg}^{2}(0.74 \AA), \mathrm{Ca}^{2+}(1.00 \AA), \mathrm{Sr}^{2+}(1.18 \AA)$ and $\mathrm{Ba}^{2+}(1.35 \AA)$ cations. The Ae-NAe' angle also widens as a result of increasing metal size. A particularly striking contrast between the 
four complexes is the largely different B-O-Ae angles: while they are nearly perfectly linear for the calcium and strontium complexes $\mathbf{1 2}_{\mathbf{2}}$ and $\mathbf{1 3}_{\mathbf{2}}$, they are much less obtuse for the magnesium and barium derivatives $\mathbf{1 1} \mathbf{2}\left(157.40(3)^{\circ}\right.$ and $\left.158.30(3)^{\circ}\right)$ and $\mathbf{4}_{\mathbf{2}}\left(160.00\left(15^{\circ}\right)\right.$.

Table 3. Summary of structural data across $\left[\mathrm{Ae}\left\{\mu_{2}-\mathrm{N}\left(\mathrm{SiMe}_{3}\right)_{2}\right\}\left(\mathrm{OB}\left\{\mathrm{CH}\left(\mathrm{SiMe}_{3}\right)_{2}\right\}_{2}\right)\right]_{2}(\mathrm{Ae}=\mathrm{Mg}, \mathrm{Ca}, \mathrm{Sr}, \mathrm{Ba})$.

\begin{tabular}{|c|c|c|c|c|c|c|c|}
\hline \multirow{2}{*}{$\begin{array}{l}\mathrm{Ae} \\
\text { Symmetry }\end{array}$} & \multicolumn{2}{|l|}{$\mathrm{Mg} \quad(\mathbf{1 1} 2)$} & \multicolumn{2}{|l|}{$\mathrm{Ca} \quad(122)$} & \multicolumn{2}{|l|}{$\mathrm{Sr}\left(\mathbf{1 3}_{2}\right)$} & \multirow{3}{*}{$\begin{array}{l}\mathrm{Ba}\left(\mathbf{4}_{2}\right)^{[27]} \\
C_{\mathrm{i}} \\
\mathrm{Ba} 1 \text { and } \mathrm{Ba} 1^{\mathrm{i}}\end{array}$} \\
\hline & \multicolumn{2}{|c|}{$C_{1}$ (pseudo- $C_{2}$ ) } & \multicolumn{2}{|c|}{$C_{1}$ (pseudo- $\left.C_{2}\right)$} & \multicolumn{2}{|l|}{$C_{1}$} & \\
\hline & $\mathrm{Mg} 1$ & $\mathrm{Mg} 2$ & $\mathrm{Ca} 1$ & $\mathrm{Ca} 2$ & Sr1 & $\mathrm{Sr} 2$ & \\
\hline \multirow[t]{2}{*}{$\mathrm{Ae}-\mathrm{N}(\AA)$} & $2.107(4)$ & $2.122(4)$ & $2.4399(11)$ & $2.4471(11)$ & $2.634(2)$ & $2.601(2)$ & $2.7210(16)$ \\
\hline & $2.117(4)$ & $2.132(4)$ & $2.4467(11)$ & $2.4499(11)$ & $2.648(2)$ & $2.635(2)$ & $2.8912(17)$ \\
\hline $\mathrm{Ae}-\mathrm{O}(\AA)$ & $1.857(3)$ & $1.863(3)$ & $2.1209(9)$ & $2.1228(10)$ & $2.2727(18)$ & $2.2751(18)$ & $2.3999(14)$ \\
\hline B-O $(\AA)$ & $1.341(5)$ & $1.351(5)$ & $1.3353(17)$ & $1.3376(18)$ & $1.351(3)$ & $1.346(3)$ & $1.332(3)$ \\
\hline N-Ae-N' $\left(^{\circ}\right)$ & $91.87(15)$ & $91.05(14)$ & 87.44(4) & $87.21(4)$ & $84.59(7)$ & $85.49(7)$ & $82.34(5)$ \\
\hline \multirow[t]{2}{*}{$\mathrm{N}-\mathrm{Ae}-\mathrm{O}\left({ }^{\circ}\right)$} & $131.46(16)$ & $130.92(16)$ & $136.22(4)$ & $135.47(4)$ & $135.97(7)$ & $132.46(7)$ & $121.64(5)$ \\
\hline & $136.67(15)$ & $137.88(15)$ & $136.30(4)$ & $137.32(4)$ & $139.43(6)$ & $141.84(6)$ & $144.18(5)$ \\
\hline$\Sigma_{\theta}(\mathrm{Ae})$ & $360.00(27)$ & $359.84(26)$ & $359.96(11)$ & $360.00(7)$ & $359.99(11)$ & $359.79(11)$ & $348.16(9)$ \\
\hline $\mathrm{B}-\mathrm{O}-\mathrm{Ae}\left({ }^{\circ}\right)$ & 157.4(3) & 158.3(3) & $178.65(9)$ & $178.92(10)$ & $178.90(16)$ & 173.51(19) & $160.00(14)$ \\
\hline $\mathrm{d}_{\text {O-plane }}(\AA)^{a}$ & $0.0493(30)$ & $0.1389(30)$ & $0.0342(9)$ & $0.0368(9)$ & $0.0529(18)$ & $0.1647(18)$ & $0.9776(14)$ \\
\hline $\mathrm{d}_{\mathrm{B} \text {-plane }}(\AA)^{b}$ & $0.0384(49)$ & $0.1263(49)$ & $0.0268(15)$ & $0.0481(15)$ & $0.0655(29)$ & $0.1487(29)$ & $1.0758(22)$ \\
\hline $\mathrm{Ae}-\mathrm{N}-\mathrm{Ae}^{\prime}\left({ }^{\circ}\right)$ & \multicolumn{2}{|c|}{$88.50(14)-88.51(14)$} & \multicolumn{2}{|c|}{$92.55(4)-92.79(4)$} & \multicolumn{2}{|c|}{$94.71(7)-95.19(7)$} & 97.66(5) \\
\hline
\end{tabular}

\section{Computational analysis}

We first examined the bonding within an homogeneous series of simple dinuclear homoleptic complexes with structural motif B (see Table 2), namely, $\left[\mathrm{Ae}\left\{\mu_{2}-\mathrm{N}\left(\mathrm{SiMe}_{3}\right)_{2}\right\}\left(\mathrm{N}\left(\mathrm{SiMe}_{3}\right)_{2}\right)\right]_{2}$, for which X-ray structural data are available for $\mathrm{Ae}=\mathrm{Mg}, \mathrm{Ca}, \mathrm{Sr}$ and $\mathrm{Ba} \cdot{ }^{[70-73]}$ For this purpose, DFT calculations were performed at the PBE0/Def2-TZVP-D3 level of theory (see Supporting Information for computational details). Relevant averaged computed data are provided in Table 4, together with some experimental metrical values. The four optimised geometries (left side of Figure 10), are in a very good agreement with their X-ray counterparts. Note that, in the four structures, the terminal nitrogen atoms $\left(\mathrm{N}_{\mathrm{t}}\right)$ retain their trigonal planar bonding mode $\left(\Sigma_{\theta}\left(\mathrm{N}_{\mathrm{t}}\right)=360^{\circ}\right.$; Table 4). This is in line with the planarity of $\mathrm{N}\left(\mathrm{SiR}_{3}\right)_{3},{ }^{[74]}$ where hyperconjugation exists between the nitrogen lone pair and the three silyl groups. The $\mathrm{N}_{\mathrm{t}}$ planarity also allows for $\pi$ donation to the Ae metal. However, the structures of the four 
complexes differ substantially with respect to the rotational conformations of their terminal disilazides. It is particularly noteworthy that in the crystal, the $\mathrm{Ba}$ and $\mathrm{Mg}$ complexes adopt different exact point symmetry groups: in $\left[\mathrm{Ba}\left\{\mu_{2}-\mathrm{N}\left(\mathrm{SiMe}_{3}\right)_{2}\right\}\left(\mathrm{N}\left(\mathrm{SiMe}_{3}\right)_{2}\right)\right]_{2}\left(C_{\mathrm{i}}\right.$ symmetry), the two planes defined by the two sets of $\left(\mathrm{N}_{\mathrm{t}} \mathrm{Si}_{2}\right)$ atoms remain roughly parallel to the $\mathrm{BaN}_{\mathrm{br}} \mathrm{BaN} \mathrm{N}_{\mathrm{br}}$ rhombus $\left(\mathrm{N}_{\mathrm{br}}=\right.$ bridging $\mathrm{N}$-atom; $\mathrm{N}_{\mathrm{t}}=$ terminal $\mathrm{N}$-atom), while for the magnesium derivative $\left(C_{2}\right.$ symmetry), the two $\left(\mathrm{N}_{\mathrm{t}} \mathrm{Si}_{2}\right)$ planes form angles of $75.8^{\circ}$ and $57.4^{\circ}$ with the $\left(\mathrm{BaN}_{\mathrm{br}}\right)_{2}$ core, respectively, and an angle of $46.8^{\circ}$ between each other. ${ }^{[70]}$ The DFT-optimised structures reproduce nicely these structural differences (Figure 10). The crystallographically determined molecular structures of the $\mathrm{Ca}$ and $\mathrm{Sr}$ species have no exact symmetry element in the crystal. That of $\mathrm{Ca}$ exhibits a rotational conformation of the terminal amido groups rather similar to that of $\mathrm{Mg}$, but with the latter two terminal $\mathrm{N}_{\mathrm{t}}\left(\mathrm{SiMe}_{3}\right)$ groups bent away from the Ae-Ae' axis. This unsymmetrical structure was also found as the most stable by DFT (Figure 10). With strontium, the DFT-optimised geometry of $\left[\mathrm{Sr}\left\{\mu_{2}-\mathrm{N}\left(\mathrm{SiMe}_{3}\right)_{2}\right\}\left(\mathrm{N}\left(\mathrm{SiMe}_{3}\right)_{2}\right)\right]_{2}$ was found to be of $C_{2}$ symmetry, but this time with the $C_{2}$ axis lying along the $\mathrm{N}_{\mathrm{br}}-\mathrm{N}_{\mathrm{br}}$ vector; hence, the four Ae and $\mathrm{N}_{\mathrm{t}}$ atoms are not perfectly aligned. Although of a different symmetry group, this structure is quite similar to that of the Ba congener. As a matter of fact, optimising $\left[\mathrm{Sr}\left\{\mu_{2}-\mathrm{N}\left(\mathrm{SiMe}_{3}\right)_{2}\right\}\left(\mathrm{N}\left(\mathrm{SiMe}_{3}\right)_{2}\right)\right]_{2}$ assuming $C_{\mathrm{i}}$ symmetry destabilises it by only $1.4 \mathrm{kcal} / \mathrm{mol}$.

Contrarily to $\mathrm{N}_{\mathrm{t}}$ atoms, the Ae centre, which adopts a perfect trigonal planar coordination in the case of $\mathrm{Mg}$, shows increasing pyramidalisation when descending group 2 and drops to $\Sigma_{\theta}(\mathrm{Ba})=350.8^{\circ}$ in the case of $\mathrm{Ba}$ (Table 4). As a result, the two $\mathrm{N}_{t}$ atoms progressively move out of the $\mathrm{AeN}_{\mathrm{br}} \mathrm{AeN}_{\mathrm{br}}$ plane; this out-of-plane shift is particularly noticeable in the case of $\mathrm{Sr}$ and $\mathrm{Ba}(\sim 0.6$ and $0.9 \AA$, respectively). Gradual pyramidalisation at $\mathrm{Ae}$ atoms in the $\left[\mathrm{Ae}\left\{\mu_{2}-\mathrm{N}\left(\mathrm{SiMe}_{3}\right)_{2}\right\}\left(\mathrm{N}\left(\mathrm{SiMe}_{3}\right)_{2}\right)\right]_{2}$ series is reminiscent of the bending observed in the heavier $\mathrm{AeX}_{2}(\mathrm{X}=\mathrm{H}$ or halide $)$ species; ${ }^{[75]}$ it is attributed to metal core polarisation and/or participation of the valence $d$-orbitals of Ae elements. ${ }^{[75-79]}$ The latter has been described as resulting from a pseudo-Jahn-Teller effect from post Hartree-Fock calculations. ${ }^{[80]}$

The atomic charges obtained from a natural atomic orbital (NAO) population analysis (Table 4) indicate strong ionicity, with Ae-charges varying within the narrow range 1.82-1.87. The corresponding valence NAO occupations indicate that the valence $s$ orbital very largely dominates the (weak) covalent component of the bonding in the case of $\mathrm{Mg}$. On the other hand, with the heavier Ae elements, the valence $(n-1) d$ orbitals are also significantly involved. Note also that with $\mathrm{Ca}, \mathrm{Sr}$ and $\mathrm{Ba}$, some core orbitals are also slightly depopulated to the benefit of their valence counterpart. From the atomic charges, it emerges that the weakly covalent interaction increases in the order $\mathrm{Mg}<\mathrm{Ba} \approx \mathrm{Sr}<\mathrm{Ca}$. This is overall consistent with the analysis of the Ae-N Wiberg bond index (WBI) values, also listed in Table 4: $\mathrm{Mg}<\mathrm{Sr}<\mathrm{Ba}<\mathrm{Ca}$. This trend is dominated by the involvement of the valence $d(\mathrm{Ae})$ orbitals. Partial occupation of the $d(\mathrm{Ae}) \mathrm{AOs}$ is not the single factor inducing Ae pyramidalisation, ${ }^{[75-79]}$ since it is maximal for $\mathrm{Ae}=\mathrm{Ca}$ which pyramidalises only moderately. Part of the $(n-1) d(\mathrm{Ae})$ population might also come from $\pi$-donation of the $\mathrm{N}_{\mathrm{t}}$ lone pair, this effect working against pyramidalisation at Ae. At any rate, all these orbital effects are small and bonding in these complexes remains chiefly ionic. Finally, 
a significant number of Ae $\cdots \mathrm{H}-\mathrm{C}$ interactions exist in each of the computed complexes. For example, in $\left[\mathrm{Ba}\left\{\mu_{2}-\mathrm{N}\left(\mathrm{SiMe}_{3}\right)_{2}\right\}\left(\mathrm{N}\left(\mathrm{SiMe}_{3}\right)_{2}\right)\right]_{2}$, eight anagostic Ba $\cdots \mathrm{C}-\mathrm{H}$ contacts shorter than the sum of the $\mathrm{H}$ and Ba van der Waals radii (3.20 ̊) are seen for each metal.

$\left[\mathrm{Ae}\left\{\mu_{2}-\mathrm{N}\left(\mathrm{SiMe}_{3}\right)_{2}\right\}\left(\mathrm{N}\left(\mathrm{SiMe}_{3}\right)_{2}\right)\right]_{2}$
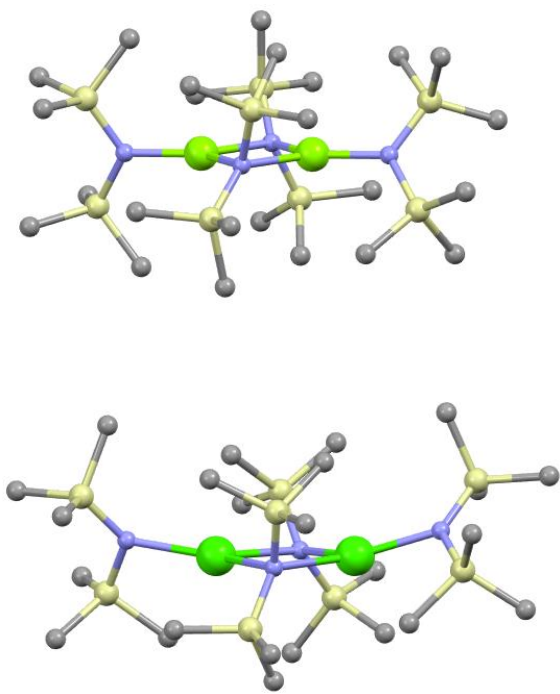

$\mathrm{Ae}=\mathrm{Ca}$

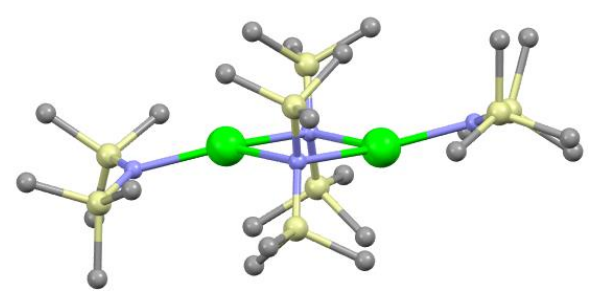

$\mathrm{Ae}=\mathrm{Sr}$

$\mathrm{Ae}=\mathrm{Mg}$
$\left[\mathrm{Ae}\left\{\mu_{2}-\mathrm{N}\left(\mathrm{SiMe}_{3}\right)_{2}\right\}\left(\mathrm{OB}\left\{\mathrm{CH}\left(\mathrm{SiMe}_{3}\right)_{2}\right\}_{2}\right)\right]_{2}$
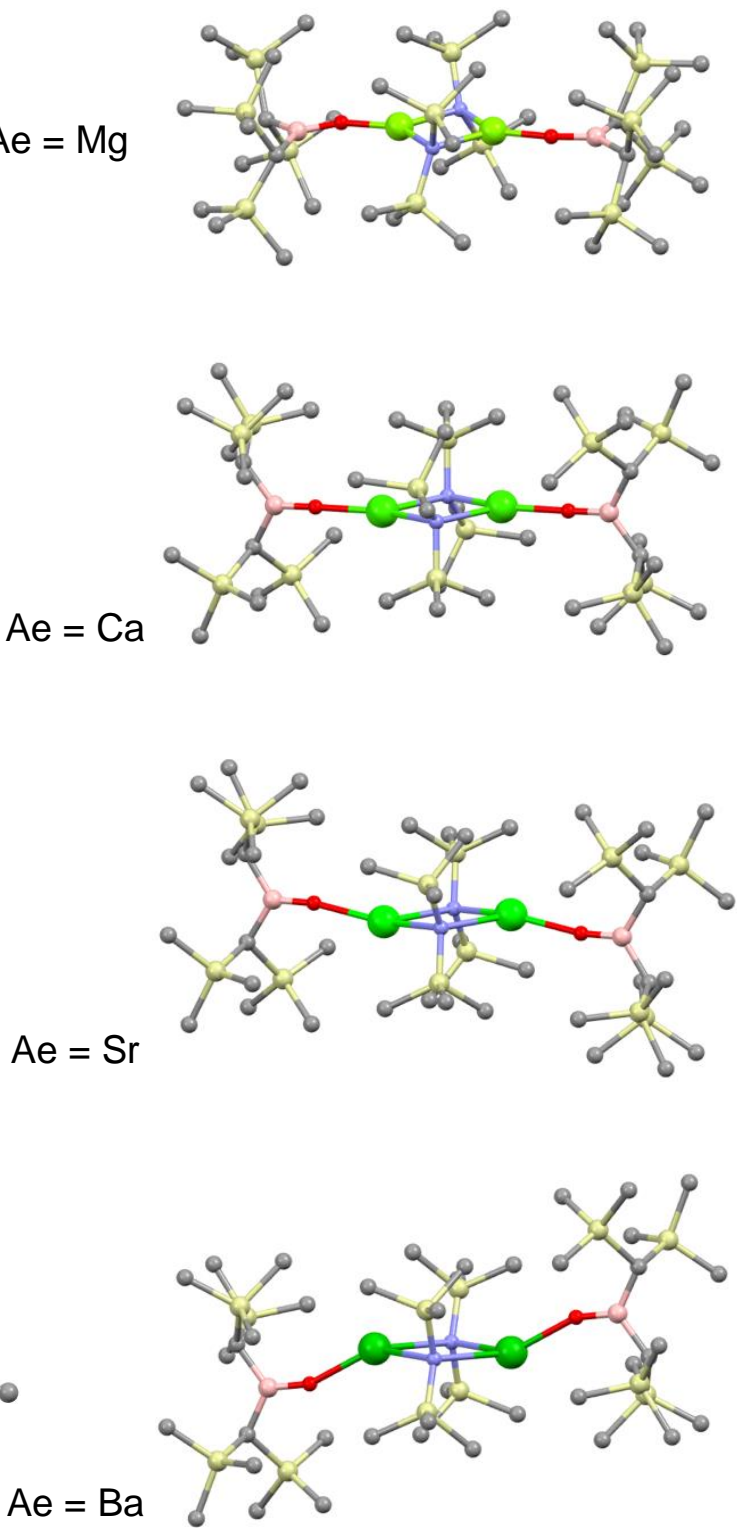

Figure 10. DFT-optimised structures of the homoleptic series $\left[\mathrm{Ae}\left\{\mu_{2}-\mathrm{N}\left(\mathrm{SiMe}_{3}\right)_{2}\right\}\left(\mathrm{N}\left(\mathrm{SiMe}_{3}\right)_{2}\right)\right]_{2}$ (left) and $\left[\mathrm{Ae}\left\{\mu_{2}-\right.\right.$ $\left.\left.\mathrm{N}\left(\mathrm{SiMe}_{3}\right)_{2}\right\}\left(\mathrm{OB}\left\{\mathrm{CH}\left(\mathrm{SiMe}_{3}\right)_{2}\right\}_{2}\right)\right]_{2}\left(\mathbf{1 1}_{\mathbf{2}}-\mathbf{1 3}_{2}\right.$ and $\mathbf{4}_{\mathbf{2}}$; right $) . \mathrm{Ae}=\mathrm{Mg}, \mathrm{Ca}, \mathrm{Sr}, \mathrm{Ba}$. Hydrogen atoms omitted for clarity. Colour of atoms: Green $=\mathrm{Ae}$; blue $=\mathrm{N}$; red $=\mathrm{O}$; beige $=\mathrm{Si}$; pink $=\mathrm{B}$; grey $=\mathrm{C}$. 
Table 4. Selected averaged computed data across $\left[\mathrm{Ae}\left\{\mu_{2}-\mathrm{N}\left(\mathrm{SiMe}_{3}\right)_{2}\right\}\left(\mathrm{N}\left(\mathrm{SiMe}_{3}\right)_{2}\right)\right]_{2}(\mathrm{Ae}=\mathrm{Mg}, \mathrm{Ca}, \mathrm{Sr}, \mathrm{Ba})$. Wiberg bond indices are given in brackets. Experimental averaged metrical values ${ }^{[70-73]}$ are reported in italics for comparison. $\mathrm{N}_{\mathrm{t}}$ and $\mathrm{N}_{\mathrm{b}}$ refer to the terminal and bridging ligand, respectively.

\begin{tabular}{|c|c|c|c|c|c|}
\hline \multicolumn{2}{|c|}{$\mathrm{Ae}$} & $\mathrm{Mg}$ & $\mathrm{Ca}$ & $\mathrm{Sr}$ & $\mathrm{Ba}$ \\
\hline \multicolumn{2}{|c|}{ Symmetry } & $C_{2}{ }^{a}$ & $\bar{C} C_{1}$ & $C_{2}{ }^{b}$ & $C_{\mathrm{i}}$ \\
\hline \multirow{2}{*}{\multicolumn{2}{|c|}{$\operatorname{Ae}-\mathrm{N}_{\mathrm{b}}(\AA)$}} & $2.128[0.025]$ & $2.454[0.045]$ & $2.609[0.040]$ & $2.803[0.042]$ \\
\hline & & 2.152 & 2.4786 & 2.635 & 2.822 \\
\hline \multirow{2}{*}{\multicolumn{2}{|c|}{$\operatorname{Ae}-\mathrm{N}_{\mathrm{t}}(\AA)$}} & $1.967[0.038]$ & 2.274 [0.097] & $2.416[0.080]$ & $2.552[0.088]$ \\
\hline & & 1.976 & 2.274 & 2.433 & 2.577 \\
\hline \multirow{2}{*}{\multicolumn{2}{|c|}{$\left.\mathrm{N}_{\mathrm{b}}-\mathrm{Ae}-\mathrm{N}_{\mathrm{b}}{ }^{\prime}{ }^{\circ}\right)$}} & 95.7 & 88.6 & 84.3 & 82.7 \\
\hline & & 95.9 & 89.2 & 83.9 & 81.9 \\
\hline \multirow{2}{*}{\multicolumn{2}{|c|}{$\mathrm{N}_{\mathrm{b}}-\mathrm{Ae}-\mathrm{N}_{\mathrm{t}}\left(^{\circ}\right)$}} & 132.1 & 134.6 & 135.6 & 134.1 \\
\hline & & 132.2 & 134.8 & 136.8 & 134.8 \\
\hline \multirow{2}{*}{\multicolumn{2}{|c|}{$\Sigma_{\theta}(\mathrm{Ae})\left(^{\circ}\right)$}} & 360.0 & 357.8 & 355.6 & 350.8 \\
\hline & & 360.0 & 358.8 & 357.5 & 351.5 \\
\hline \multirow{2}{*}{\multicolumn{2}{|c|}{$\Sigma_{\theta}\left(\mathrm{N}_{\mathrm{t}}\right)\left(^{\circ}\right)$}} & 360.0 & 359.7 & 359.8 & 360.0 \\
\hline & & 360.0 & 359.7 & 359.9 & 360.0 \\
\hline \multirow{2}{*}{\multicolumn{2}{|c|}{$D_{\text {Nt-plane }}(\AA)^{\mathrm{c}}$}} & 0.000 & 0.556 & 0.634 & 0.949 \\
\hline & & 0.000 & 0.444 & 0.478 & 0.915 \\
\hline \multirow{2}{*}{\multicolumn{2}{|c|}{$\mathrm{Ae}-\mathrm{N}_{\mathrm{b}}-\mathrm{Ae}^{\prime}\left({ }^{\circ}\right)$}} & 84.3 & 91.3 & 95.7 & 97.3 \\
\hline & & 84.1 & 90.7 & 96.1 & 98.1 \\
\hline \multirow{3}{*}{$\begin{array}{l}\text { Atomic } \\
\text { charges }\end{array}$} & $\mathrm{Ae}$ & $\begin{array}{c}1.88 \\
3 \mathrm{~s}^{0.10} 3 \mathrm{p}^{0.01} 3 \mathrm{~d}^{0.01}\end{array}$ & $\begin{array}{c}1.82 \\
4 \mathrm{~s}^{0.08} 4 \mathrm{p}^{0.01} 3 \mathrm{~d}^{0.09}\end{array}$ & $\begin{array}{c}1.84 \\
5 \mathrm{~s}^{0.07} 5 \mathrm{p}^{0.01} 4 \mathrm{~d}^{0.07}\end{array}$ & $\begin{array}{c}1.87 \\
6 \mathrm{~s}^{0.07} 6 \mathrm{p}^{0.01} 5 \mathrm{~d}^{0.07}\end{array}$ \\
\hline & $\mathrm{N}_{\mathrm{b}}$ & -2.03 & -1.93 & -1.94 & -1.92 \\
\hline & $\mathrm{N}_{\mathrm{t}}$ & -1.97 & -1.88 & -1.88 & -1.88 \\
\hline $\begin{array}{l}{ }^{a} C_{2} \text { axis } \\
\text { mean pla }\end{array}$ & & e Ae-Ae' vector. & axis parallel to th & $\mathrm{I}_{\mathrm{b}}$ ' vector. ${ }^{c}$ Dista & $\mathrm{N}_{\mathrm{t}}$ to the $\left(\mathrm{AeN}_{\mathrm{b}}\right)_{2}$ \\
\hline
\end{tabular}

We now shift our attention to the analysis of the set of heteroleptic complexes $\left[\operatorname{Ae}\left\{\mu_{2}-\right.\right.$ $\left.\left.\mathrm{N}\left(\mathrm{SiMe}_{3}\right)_{2}\right\}\left(\mathrm{OB}\left\{\mathrm{CH}\left(\mathrm{SiMe}_{3}\right)_{2}\right\}_{2}\right)\right]_{2}\left(\mathrm{Ae}=\mathrm{Mg}, \mathrm{Ca}, \mathrm{Sr}, \mathrm{Ba}\right.$, i.e. $\mathbf{1 1}_{\mathbf{2}}-\mathbf{1 3}_{\mathbf{2}}$ and $\left.\mathbf{4}_{\mathbf{2}}\right)$; relevant computed data are provided in Table 5. The four optimised geometries (Figure 10, right) were found to be rather floppy, a recognised feature of Ae-centred molecules, ${ }^{[79]}$ with their lowest energy structure being of (or very close to) $C_{\mathrm{i}}$ symmetry. Their optimised metrical data are in good agreement with their X-ray counterparts (Tables 3 and 5). As in the homoleptic series, the geometry about Ae pyramidalises when going down group 2, to reach $\Sigma_{\theta}(\mathrm{Ba})=343.7^{\circ}$ in the case of the barium complex $\mathbf{4}_{2}$. The experimental trend along this series for the $\mathrm{O}$ and $\mathrm{B}$ out-of-plane shifting mentioned above is thus nicely reproduced by DFT. As seen for the homoleptic series of amides, the covalent component of the Ae-ligand bonding involves essentially the valence $s(\mathrm{Ae})$ orbital in the case of $\mathrm{Mg}$, and both $s(\mathrm{Ae})$ and $d(\mathrm{Ae})$ orbitals for the heavier elements. The experimental tendency for larger B-O-Ae angles in the cases of $\mathrm{Ca}$ and $\mathrm{Sr}$ is also reproduced by DFT. It is associated with larger B-O Wiberg indices, suggesting a larger tendency of the 
oxygen atoms for $s p$ hybridisation, and hence (slightly) larger $\pi$-donation to Ae. Taken collectively, the data of Table 5 suggests increasing covalency in the order $\mathrm{Mg}<\mathrm{Sr}<\mathrm{Ba}<\mathrm{Ca}$. However, as for the homoleptic series discussed above, the covalent component of the bonds remains weak compared to the ionic contribution. Several Ae $\cdots \mathrm{H}-\mathrm{C}$ anagostic interactions are also present in all complexes of the heteroleptic set. For example, for the barium complex $\mathbf{4}_{2}$, eight Ba $\cdots \mathrm{H}-\mathrm{C}$ contacts shorter than $3.20 \AA$ are seen for each $\mathrm{Ba}$ atom; this is fully consistent with the crystallographically established molecular structure for this complex. ${ }^{[27]}$ Several additional Ba $\cdots \mathrm{H}$ contacts slightly larger than $3.20 \AA$ are also detected.

Table 5. Selected computed data for the series $\left[\mathrm{Ae}\left\{\mu_{2}-\mathrm{N}\left(\mathrm{SiMe}_{3}\right)_{2}\right\}\left(\mathrm{OB}\left\{\mathrm{CH}\left(\mathrm{SiMe}_{3}\right)_{2}\right\}_{2}\right)\right]_{2}(\mathrm{Ae}=\mathrm{Mg}, \mathrm{Ca}, \mathrm{Sr}, \mathrm{Ba}$, $\mathbf{1 1}_{2}-\mathbf{1 3}_{2}$ and $\mathbf{4}_{2}$ ). Wiberg bond indices are given into brackets.

\begin{tabular}{|c|c|c|c|c|c|}
\hline \multicolumn{2}{|c|}{$\mathrm{Ae}$} & $\operatorname{Mg}\left(\mathbf{1 1}_{2}\right)$ & $\mathrm{Ca}\left(\mathbf{1 2}_{2}\right)$ & $\operatorname{Sr}(\mathbf{1 3 2})$ & $\mathrm{Ba}\left(\mathbf{4}_{2}\right)$ \\
\hline \multicolumn{2}{|c|}{ Symmetry } & Pseudo- $C_{\mathrm{i}}$ & $C_{\mathrm{i}}$ & $C_{\mathrm{i}}$ & $C_{\mathrm{i}}$ \\
\hline \multirow{2}{*}{\multicolumn{2}{|c|}{ Ae-N (̊) }} & $2.103[0.029]$ & $2.403[0.048]$ & $2.557[0.040]$ & $2.717[0.044]$ \\
\hline & & $2.110[0.030]$ & $2.516[0.034]$ & $2.670[0.027]$ & $2.851[0.031]$ \\
\hline \multicolumn{2}{|c|}{$\mathrm{Ae}-\mathrm{O}(\AA)$} & $1.858[0.042]$ & $2.117[0.082]$ & $2.260[0.065]$ & $2.391[0.070]$ \\
\hline \multicolumn{2}{|c|}{$\mathrm{B}-\mathrm{O}(\AA)$} & $1.343[1.022]$ & 1.336 [1.059] & $1.332[1.065]$ & $1.330[1.054]$ \\
\hline \multicolumn{2}{|c|}{ N-Ae-N' $\left(^{\circ}\right)$} & 91.8 & 84.9 & 84.3 & 83.2 \\
\hline \multirow{2}{*}{\multicolumn{2}{|c|}{$\mathrm{N}-\mathrm{Ae}-\mathrm{O}\left(^{\circ}\right)$}} & 130.2 & 126.9 & 125.4 & 121.9 \\
\hline & & 138.0 & 148.0 & 145.1 & 138.7 \\
\hline \multicolumn{2}{|c|}{$\Sigma_{\theta}(\mathrm{Ae})\left({ }^{\circ}\right)$} & 360.0 & 359.8 & 354.8 & 343.7 \\
\hline \multicolumn{2}{|c|}{$\mathrm{B}-\mathrm{O}-\mathrm{Ae}\left(^{\circ}\right)$} & 154.5 & 174.1 & 168.7 & 158.2 \\
\hline \multicolumn{2}{|c|}{$\mathrm{d}_{\text {O-plane }}(\AA)^{a}$} & 0.029 & 0.126 & 0.626 & 1.173 \\
\hline \multicolumn{2}{|c|}{$\mathrm{d}_{\text {B-plane }}(\AA)^{b}$} & 0.176 & 0.145 & 0.750 & 1.351 \\
\hline \multicolumn{2}{|c|}{$\mathrm{Ae}-\mathrm{N}-\mathrm{Ae}^{\prime}\left(^{\circ}\right)$} & 88.2 & 95.1 & 95.7 & 96.8 \\
\hline \multirow{4}{*}{$\begin{array}{l}\text { Atomic } \\
\text { charges }\end{array}$} & $\mathrm{Ae}$ & $\begin{array}{c}1.88 \\
3 \mathrm{c}^{0.11} 3 \mathrm{n}^{0.01} 3 \mathrm{~d}^{0.01}\end{array}$ & $\begin{array}{c}1.85 \\
0 \mathrm{~s}^{0.08} \mathrm{n}^{0.01} 3 \mathrm{~d}^{0.09}\end{array}$ & $\begin{array}{c}1.87 \\
5.08\end{array}$ & $\begin{array}{c}1.88 \\
0.076 \mathrm{r}^{0.07}\end{array}$ \\
\hline & $\mathrm{N}$ & $\begin{array}{c}3 \mathrm{~s}^{0.11} 3 \mathrm{p}^{0.01} 3 \mathrm{~d}^{0.01} \\
-2.03\end{array}$ & $\begin{array}{c}4 \mathrm{~s}^{0.00} 4 \mathrm{p}^{0.01} 3 \mathrm{~d}^{0.09} \\
-1.94\end{array}$ & $\begin{array}{c}5 s^{3.00} \\
-1.94\end{array}$ & 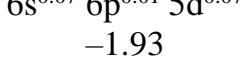 \\
\hline & $\mathrm{O}$ & -1.31 & -1.27 & -1.28 & -1.28 \\
\hline & B & 1.18 & 1.16 & 1.16 & 1.18 \\
\hline
\end{tabular}

In order to provide a rationalisation of the empirical bridging ability proposed in Figure 8, the

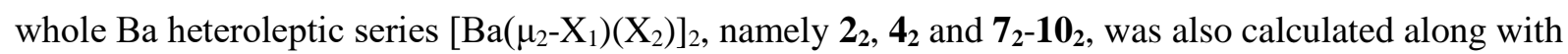
their hypothetical topological isomers $\left[\mathrm{Ba}\left(\mu_{2}-\mathrm{X}_{2}\right)\left(\mathrm{X}_{1}\right)\right]_{2}$ (denoted $\mathbf{2}_{2}{ }^{*}, \mathbf{4}_{2}{ }^{*}$ and $\left.\mathbf{7}_{\mathbf{2}}{ }^{*} \mathbf{- 1 0} \mathbf{1 0}^{*}\right)$, where $\mathrm{X}_{1}$ and $\mathrm{X}_{2}$ are chosen among $\mathrm{N}\left(\mathrm{SiMe}_{3}\right)_{2}, \mathrm{OB}\left\{\mathrm{CH}\left(\mathrm{SiMe}_{3}\right)_{2}\right\}_{2}, \mathrm{OSi}\left(\mathrm{SiMe}_{3}\right)_{3}, \mathrm{O}-2,6-\mathrm{Ph}_{2}-\mathrm{C}_{6} \mathrm{H}_{3}$ and $\mathrm{OB}(\mathrm{Tripp})_{2}$ and $\mathrm{X}_{1} \neq \mathrm{X}_{2}$. The corresponding optimised geometries are given in Figures S55-56; those for complexes $\mathbf{2}_{2}$, 
$\mathbf{4}_{\mathbf{2}}$ and $\mathbf{7}_{\mathbf{2}}-\mathbf{1 0}_{\mathbf{2}}$ are in good agreement with their experimental $\mathrm{X}$-ray analogues. In particular, the $\mathrm{Ba} \cdots \mathrm{H}-$ $\mathrm{C}$ and $\mathrm{Ba} \cdots \mathrm{C}(\pi)$ secondary interactions are well reproduced in the optimised structures. Consistently with the fact they were not observed experimentally, the topological isomers of $\mathbf{2}_{\mathbf{2}}^{*}, \mathbf{4}_{\mathbf{2}}{ }^{*}, \mathbf{7}_{\mathbf{2}}{ }^{*}, \mathbf{8}_{\mathbf{2}}{ }^{*}, \mathbf{9}_{\mathbf{2}}{ }^{*}$, and $\mathbf{1 0}_{2} *$ were found systematically less stable by $17.5,13.1,24.2,5.5,10.8$ and $7.1 \mathrm{kcal} / \mathrm{mol}$, respectively. Therefore, the DFT simulations reproduce the empirical trend displayed in Figure 8. As shown above, the nature of the $\mathrm{Ba}-\mathrm{O}$ or Ba-N bonds in these complexes is largely ionic in character. It follows that the $\mathrm{O}$ and $\mathrm{N}$ atomic charge on the "free ligand" is likely to be an important parameter in the prediction of the bonding strength and mode: the more negative the charge, the stronger the bond, but also the more favoured the bridging position over the terminal one. A negatively charged atom is indeed expected to interact in a stronger way with two metal cations, as compared with a single one, provided the metal-ligand distances do not differ importantly. The absolute values of the computed $\mathrm{N}$ and $\mathrm{O}$ natural atomic charges, and the potential bridging preference with them, are increasing in the order: $\left[\mathrm{O}\left(2,6-\mathrm{Ph}_{2}-\mathrm{C}_{6} \mathrm{H}_{3}\right)\right]^{-}(-0.72)<\left[\mathrm{OB}(\text { Tripp })_{2}\right]^{-}(-0.97)<\left[\mathrm{OB}\left\{\mathrm{CH}\left(\mathrm{SiMe}_{3}\right)_{2}\right\}\right]^{-}(-1.07)<\left[\mathrm{OSi}\left(\mathrm{SiMe}_{3}\right)_{3}\right]^{-}(-$ $1.29)<\left[\mathrm{N}\left(\mathrm{SiMe}_{3}\right)_{2}\right]^{-}(-1.75)$. Obviously, this trend does not follow that given in Figure 8; it is only consistent with the configurations of $\left[\mathrm{Ba}\left\{\mu_{2}-\mathrm{N}\left(\mathrm{SiMe}_{3}\right)_{2}\right\}\left(\mathrm{OB}\left\{\mathrm{CH}\left(\mathrm{SiMe}_{3}\right)_{2}\right\}_{2}\right)_{2} \quad\left(\mathbf{4}_{2}\right)\right.$ and $\left[\mathrm{Ba}\left\{\mu_{2}-\right.\right.$ $\left.\left.\mathrm{OSi}\left(\mathrm{SiMe}_{3}\right)_{3}\right\}\left(\mathrm{OB}\left\{\mathrm{CH}\left(\mathrm{SiMe}_{3}\right)_{2}\right\}_{2}\right)\right]_{2}\left(\mathbf{8}_{2}\right)$. Although it is only marginal, one may then wonder about the potential ability of covalent bonding in these complexes. The ligand donating abilities are related to the energies and localisations of their lone-pair orbitals. Whereas a terminal ligand needs a single donating orbital (or a combination thereof) of $\sigma$-type, a bridging ligand needs to use two donating orbitals, one of $\sigma$-type and one of $\pi$-type. The more available the $\pi$-type orbital, the more privileged the bridging position over the terminal one. It turns out that all the investigated ligands have their HOMO containing the $\pi$-type lone pair, as illustrated in their Kohn-Sham MO diagrams (Figure S57). All of them have their $\sigma$-type lone pair lying much lower, except for $\left[\mathrm{N}\left(\mathrm{SiMe}_{3}\right)_{2}\right]^{-}$in which the two donating orbitals are close in energy. From their $\pi$-type HOMO energies, the bridging preference increases as: $\left.\left[\mathrm{OB}\left\{\mathrm{CH}\left(\mathrm{SiMe}_{3}\right)_{2}\right\}\right]^{-}(-1.77 \mathrm{eV}) \approx\left[\mathrm{OB}(\text { Tripp })_{2}\right\}\right]^{-}(-1.70 \mathrm{eV})<\left[\mathrm{OSi}\left(\mathrm{SiMe}_{3}\right)_{3}\right]^{-}(-1.55 \mathrm{eV})<$ $\left[\mathrm{N}\left(\mathrm{SiMe}_{3}\right)_{2}\right]^{-}(-1.37 \mathrm{eV})<\left[\mathrm{O}\left(2,6-\mathrm{Ph}_{2}-\mathrm{C}_{6} \mathrm{H}_{3}\right)\right]^{-}(-1.27 \mathrm{eV})$. Again, and as expected owing to the weak covalent character in these complexes, no clear agreement with the empirical trend in Figure 8 is seen.

From these considerations, it follows that the secondary interactions play an important role in the isomer preference. Unsurprisingly, the $\mathrm{Ba} \cdots \mathrm{C}(\pi)$ bonding in $\mathbf{7}_{\mathbf{2}}, \mathbf{9}_{\mathbf{2}}$ and $\mathbf{1 0}_{\mathbf{2}}$ plays a key role in favouring the bridging position of the $\left.\left[\mathrm{OB}(\mathrm{Tripp})_{2}\right\}\right]^{-}$and $\left[\mathrm{O}\left(2,6-\mathrm{Ph}_{2}-\mathrm{C}_{6} \mathrm{H}_{3}\right)\right]^{-}$ligands. The corresponding optimised $\mathrm{Ba} \cdots \mathrm{C}$ distances of 3.0-3.3 $\AA$ are only moderately larger than that in $\mathrm{BaCp}_{2}\left(3.0-3.1 \AA\right.$ ) $\AA^{[81]}$ The case of $\left[\mathrm{Ba}\left\{\mu_{2}-\mathrm{OSi}\left(\mathrm{SiMe}_{3}\right)_{3}\right\}\left\{\mathrm{N}\left(\mathrm{SiMe}_{3}\right)_{2}\right\}\right]_{2}$ ( $\left.\mathbf{2}_{\mathbf{2}}\right)$, which does not possess any $\pi$ system, is particularly telling: whereas the siloxide $\left[\mathrm{OSi}\left(\mathrm{SiMe}_{3}\right)_{3}\right]^{-}$is less negatively polarised than $\left[\mathrm{N}\left(\mathrm{SiMe}_{3}\right)_{2}\right]^{-}$, it still prefers the bridging position between the two Ba atoms. The optimised geometries of $\mathbf{2}_{\mathbf{2}}$ and its topological isomer $\left[\mathrm{Ba}\left\{\mu_{2}-\mathrm{N}\left(\mathrm{SiMe}_{3}\right)_{2}\right\}\left\{\mathrm{OSi}\left(\mathrm{SiMe}_{3}\right)_{3}\right\}\right]_{2}\left(\mathbf{2}_{2} *\right.$, Figure S55) differ in their compactness, for $\mathbf{2}_{\mathbf{2}}$ is rather spherical, while $\mathbf{2}_{\mathbf{2}} *$ is much more oblong. Consistently, the dispersion energy computed 
through Grimme's empirical corrections ${ }^{[82]}$ for $\mathbf{2}_{\mathbf{2}}$ is $9.0 \mathrm{kcal} / \mathrm{mol}$ lower than in $\mathbf{2}_{2}{ }^{*}$. This difference is indicative of larger van der Waals and steric stabilisations in $\mathbf{2}_{2}$. Another part of these secondary nonbonding interaction energies is likely to be contained into the DFT electronic energy. On the other hand, in complexes $\mathbf{4}_{2}$ and $\mathbf{8}_{2}$, the dispersion energy actually favours the isomers $\mathbf{4}_{2}^{*}$ and $\mathbf{8}_{2} *$ not seen experimentally. One may then infer that the preference for the actual structures of $\mathbf{4}_{2}$ and $\mathbf{8}_{\mathbf{2}}$ is dictated by the direct ligand-to-Ba bonding, which is dominated by ionicity.

In summary, the ability of $\mathrm{N}$ - and $\mathrm{O}$-based ligands for bridging two $\mathrm{Ba}^{2+}$ cations is a composite of several contributions. With sufficiently non-bulky ligands, since the $\mathrm{Ba}-\mathrm{N}$ or $\mathrm{Ba}-\mathrm{O}$ bond is mainly ionic, the more negatively polarised (on $\mathrm{N}$ or $\mathrm{O}$ ) ligand prefers occupying the bridging position, thus maximizing electrostatic interactions. In the case of homoleptic dinuclear complexes of such "small" ligands, since the bridging position is preferred, the number of bridging ligands will be maximised to three, as actually seen in $\mathbf{1}_{2}{ }^{[29]}$ and, for instance, in $\mathrm{Ba}_{2} \mathrm{Cl}_{4}{ }^{[75,79]}$ In these two examples, we found the triply bridged structural motif C (Table 2) to be more stable that the "regular" doubly bridged motif B by 13.6 and $9.2 \mathrm{kcal} / \mathrm{mol}$ respectively. Interestingly, the quadruply bridged structure $\left[\mathrm{Ba}\left(\mu_{2}-\mathrm{Cl}\right)_{2}\right]_{2}$ of $D_{4 h}$ symmetry is also a local energy minimum for $\mathrm{Ba}_{2} \mathrm{Cl}_{4}{ }^{[75]}$ At our level of calculations, it is 15.0 $\mathrm{kcal} / \mathrm{mol}$ less stable than the $C_{3 \mathrm{v}} \mathrm{Ba}_{2}\left(\mu_{2}-\mathrm{Cl}\right)_{3} \mathrm{Cl}$ minimum. With four bridging chlorides, the $\mathrm{Ba}-\mathrm{Cl}$ electrostatic interactions are maximised, but the repulsions between the ligands disfavour this configuration. With bulkier ligands, secondary metal-ligand bonding interactions are expected to come

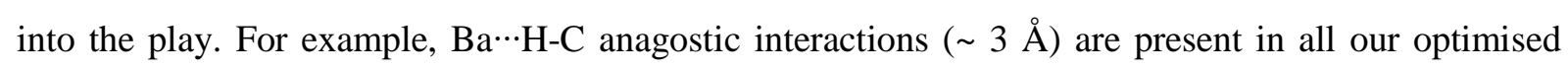
structures and their (relative) weakness can be compensated by their large number. More specific but stronger interactions can also occur, such as the above-mentioned $\mathrm{Ba} \cdots \mathrm{C}(\pi)$ more covalent interactions with ligands that contain a $\pi$-system (e.g. a $\mathrm{C}_{6}$ aromatic ring), but also electrostatic $\mathrm{Ba} \cdots \mathrm{F}$ interactions in the case of fluorinated ligands. We have shown on model calculations that the magnitude of a single $\mathrm{Ca} \cdots \mathrm{F}$ bonding energy could reach $9-14 \mathrm{kcal} / \mathrm{mol} .{ }^{[49]}$ Similar values can be expected for barium. It should be noted that the possibility for such secondary interactions could occur in both bridging and terminal positions of the ligand, making the induction of the bridging $v s$. terminal choice also dependant of other factors, such as the shape and flexibility of the co-ligand. Indeed, ligand $\cdots$ ligand interactions play also a crucial role in the structural determinism of these complexes. They result from a compromise between steric repulsions and van der Waals bonding (dispersion forces), in particular through $\mathrm{H} \cdots \mathrm{H}$ interactions. The latter tend to favour pseudo-spherical shapes (as in $\mathbf{2}_{2}$ ) to the detriment of more open structures. The main learning to take away is that the bridging ability of a specific ligand depends of course on its various intrinsic features but also, in a significant part, on the way these characteristics can be expressed in relation with those of its other co-ligand. Therefore, it seems wise to consider the trend given in Figure 8 as relative to the considered ligand interplay. Introducing other ligand combinations may partly contradict this relative classification. 


\section{Concluding comments}

Building on our earlier syntheses of low-coordinate barium-boryloxides and barium-siloxides, ${ }^{[27,29]}$ we have prepared here several homoleptic and heteroleptic barium complexes supported by various monoanionic O-based ligands. The complexes form dinuclear species that have been structurally characterised by X-ray diffraction crystallography. The siloxide, boryloxide and even phenoxide ligands are shown to occupy in turn bridging or terminal positions, depending on the specific case and ligand combination. Extended to the structural data already available for complexes bearing these O-based ligands, including for heteroleptic compounds that also contain the $\left[\mathrm{N}\left(\mathrm{SiMe}_{3}\right)_{2}\right]^{-}$amide, Table 2 highlights a diversity of coordination patterns, some of them being unexpected. The experimentallyestablished propensity to occupy bridging positions, as opposed to terminal ones, in heteroleptic dimers, increases with $\left.\left[\mathrm{OB}\left\{\mathrm{CH}\left(\mathrm{SiMe}_{3}\right)_{2}\right\}_{2}\right)\right]^{-}<\left[\mathrm{N}\left(\mathrm{SiMe}_{3}\right)_{2}\right]^{-}<\left[\mathrm{OSi}\left(\mathrm{SiMe}_{3}\right)_{3}\right]^{-}<\left[\mathrm{O}\left(2,6-\mathrm{Ph}_{2}-\mathrm{C}_{6} \mathrm{H}_{3}\right)\right]^{-}<$ $\left[\mathrm{OB}\left(2,4,6-{ }^{-} \mathrm{Pr}_{3}-\mathrm{C}_{6} \mathrm{H}_{2}\right)_{2}\right]^{-}$. In the solid state, most of these complexes display secondary Ba $\cdots \mathrm{H}-\mathrm{C}, \mathrm{Ba} \cdots \mathrm{F}$ and $\mathrm{Ba} \cdots \mathrm{C}(\pi)$ secondary interactions which not only enhances profoundly their stability as demonstrated on several occasions, ${ }^{[11,49]}$ but also their structures in the solid state. In these complexes bearing "simple", monodentate ligand, the coordination of Lewis bases, such as thf, suppresses partly or entirely these secondary interactions. This needs not be always the case, as we have shown earlier that combinations of multiple $\mathrm{Ca} \cdots \mathrm{H}-\mathrm{C}, \mathrm{Ca} \cdots \mathrm{F}$ and $\mathrm{Ca} \cdots \mathrm{C}(\pi)$ secondary interactions within sterically congested calcium complexes supported by functionalised aminoether-fluoroalkoxide effectively prevented the coordination of thf onto the metal. ${ }^{[83]}$

The comparison of crystallographic data obtained for the homologous set of heteroleptic complexes $\left[\mathrm{Ae}\left\{\mu_{2}-\mathrm{N}\left(\mathrm{SiMe}_{3}\right)_{2}\right\}\left(\mathrm{OB}\left\{\mathrm{CH}\left(\mathrm{SiMe}_{3}\right)_{2}\right\}_{2}\right)\right]_{2}(\mathrm{Ae}=\mathrm{Mg}, \mathrm{Ca}, \mathrm{Sr}$ and $\mathrm{Ba})$ shows that structural features are generally well reproduced across the whole series, although some subtle variations are observed, notably with the smaller magnesium. It therefore feels legitimate to assume that the main conclusions drawn from the detailed examination of the structures of barium complexes can be extrapolated to, at least, calcium and strontium; this is also confirmed by DFT computations.

Our DFT calculations on series of homo- and heteroleptic dinuclear complexes of barium and related alkaline earths, including magnesium, stress on the largely prevailing ionic character of ligandAe bonding. The minor covalent component of the bonding is mainly controlled by the valence $s$ atomic orbital of the alkaline earth, together with the valence $d$ atomic orbital in the case of the heavier $\mathrm{Ca}, \mathrm{Sr}$ and Ba elements. The participation of $d$ atomic orbitals favours non-planarity of the coordination mode for the heavier Ae metals, associated with an increased floppiness of the complexes. The pre-eminence of the ionic character of the Ae-ligand bond favours bridging coordination, the number of bridging ligands (most often two) being regulated by steric factors. In the case of heteroleptic species, the relative ligand preference for bonding vs. terminal positions is not determined by the ligand abilities to make stronger/weaker direct terminal or bridging bonds with the metal, but rather by the secondary (but nonnegligible) interactions that can occur between the Ae metal and the ligand. This is well exemplified by 
the compounds discussed herein, which exhibit a range of anagostic (and numerous) Ae $\cdots \mathrm{H}$, covalent $\mathrm{Ae} \cdots \mathrm{C}(\pi)$ and/or ionic $\mathrm{Ae} \cdots \mathrm{F}$ interactions.

Considering the importance of well understood and controlled structure-reactivity relationships for the design of efficient alkaline-earth homogeneous catalysts, and in particular for those constructed with oxygen-based ligands, the data and analysis presented herein should constitute a useful guideline to assist synthetic organometallic main group chemists in their future endeavours. Comforted with this knowledge and with the further confirmation of the key role of secondary interactions in alkaline-earth chemistry, we now intend to prepare the simplest and, arguably, most versatile of O-ligated complexes: soluble, well-defined barium alkoxides and their lighter congeners.

\section{Acknowledgements}

The authors thank the ANR for funding (ANR-17-CE07-0003-01) and for the provision of a PhD studentship to J. H. The GENCI (Grand Equipment National de Calcul Intensif) is acknowledged for HPC resources (Project A0050807367).

\section{Conflicts of interest}

There are no conflicts of interest to declare.

\section{Author Contributions}

E. Le Coz and J. Hammoud performed synthetic experimental work and data analysis. T. Roisnel, M. Cordier and V. Dorcet performed the XRD analyses. J.-Y. Saillard and S. Kahlal carried out all computational work and took part to the writing of the draft. J.-F. Carpentier participated to the design of experiments and analysis of experimental data. Y. Sarazin was the lead investigator; he participated to the design of experiments, analysis of experimental data and writing of the draft.

\section{Notes and references}

[1] S. Harder, Chem. Rev. 2010, 110, 3852.

[2] M. R. Crimmin, M. S. Hill, Top. Organomet. Chem. 2013, 45, 191.

[3] M. S. Hill, D. J. Liptrot, C. Weetman, Chem. Soc. Rev. 2016, 45, 972.

[4] Early Main Group Metal Catalysis: Concepts and Reactions, ed. S. Harder, Wiley-VCH Verlag $\mathrm{GmbH} \& \mathrm{Co}, 2020$.

[5] S. Harder, F. Feil, K. Knoll, Angew. Chem. Int. Ed. 2001, 40, 4261.

[6] Y. Sarazin, B. Liu, T. Roisnel, L. Maron, J.-F. Carpentier, J. Am. Chem. Soc. 2011, 133, 9069.

[7] M. R. Crimmin, I. J. Casely, M. S. Hill, J. Am. Chem. Soc. 2005, 127, 2042.

[8] F. Buch, J. Brettar, S. Harder, Angew. Chem. Int. Ed. 2006, 45, 2741.

[9] J. Spielmann, F. Buch, S. Harder, Angew. Chem. Int. Ed. 2008, 47, 9434. 
[10] A. G. M. Barrett, C. Brinkmann, M. R. Crimmin, M. S. Hill, P. Hunt, P. A. Procopiou, J. Am. Chem. Soc. 2009, 131, 12906.

[11] P. Jochmann, J. P. Davin, T. P. Spaniol, L. Maron, J. Okuda, Angew. Chem. Int. Ed. 2012, 51, 4452 .

[12] B. Liu, T. Roisnel, J.-F. Carpentier, Y. Sarazin, Angew. Chem. Int. Ed. 2012, 51, 4943.

[13] H. Bauer, M. Alonso, C. Fischer, B. Rösch, H. Elsen, S. Harder, Angew. Chem. Int. Ed. 2018, 57, 15177.

[14] A. S. S. Wilson, C. Dinoi, M. S. Hill, M. F. Mahon, L. Maron, Angew. Chem. Int. Ed. 2018, 57, 15500.

[15] F. M. Younis, S. Krieck, T. M. Al-Shboul, H. Görls, M. Westerhausen, Inorg. Chem. 2016, 55, 4676.

[16] H. Bauer, M. Alonso, C. Färber, H. Elsen, J. Pahl, A. Causero, G. Ballmann, F. de Proft, S. Harder, Nat. Catal. 2018, 1, 40

[17] J. Martin, C. Knüpfer, J. Eyselein, C. Färber, S. Grams, J. Langer, K. Thum, M. Wiesinger, S. Harder, Angew. Chem. Int. Ed. 2020, 59, 9102.

[18] L. Zhao, X. Shi and J. Cheng, ACS Catal. 2021, 11, 2041.

[19] A. G. M. Barrett, M. R. Crimmin, M. S. Hill, P. B. Hitchcock, P. A. Procopiou, Organometallics 2007, 26, 4076.

[20] J. Spielmann, S. Harder, J. Am. Chem. Soc. 2009, 131, 5064.

[21] M. S. Hill, M. Hodgson, D. J. Liptrot, M. F. Mahon, Dalton Trans. 2011, 40, 7783.

[22] D. J. Liptrot, M. S. Hill, M. F. Mahon, A. S. S. Wilson, Angew. Chem. Int. Ed. 2015, 54, 13362.

[23] J. Spielmann, G. Jansen, H. Bandmann, S. Harder, Angew. Chem. Int. Ed. 2008, 47, 6290.

[24] M. S. Hill, D. J. Liptrot, D. J. MacDougall, M. F. Mahon, T. P. Robinson, Chem. Sci. 2013, 4, 4212.

[25] C. Bellini, J.-F. Carpentier, S. Tobisch, Y. Sarazin, Angew. Chem. Int. Ed. 2015, 54, 7679.

[26] C. Bellini, C. Orione, J.-F. Carpentier, Y. Sarazin, Angew. Chem. Int. Ed. 2016, 55, 3744.

[27] E. Le Coz, V. Dorcet, T. Roisnel, S. Tobisch, J.-F. Carpentier, Y. Sarazin, Angew. Chem. Int. Ed. 2018, 57,11747 .

[28] E. Le Coz, Z. Zhang, T. Roisnel, L. Cavallo, L. Falivene, J.-F. Carpentier, Y. Sarazin, Chem. Eur. J. 2020, 26, 3535 .

[29] E. Le Coz, S. Kahlal, J.-Y. Saillard, T. Roisnel, V. Dorcet, J.-F. Carpentier, Y. Sarazin, Chem. Eur. J. 2019, 25, 13509.

[30] S. Tobisch, Chem. Eur. J. 2015, 21, 6765.

[31] P. M. Chapple, Y. Sarazin, Eur. J. Inorg. Chem. 2020, 3321.

[32] T. X. Gentner, B. Rösch, K. Thum, J. Langer, G. Ballmann, J. Pahl, W. A. Donaubauer, F. Hampel, S. Harder, Organometallics 2019, 38, 2485. 
[33] P. M. Chapple, S. Kahlal, J. Cartron, T. Roisnel, V. Dorcet, M. Cordier, J.-Y. Saillard, J.-F. Carpentier, Y. Sarazin, Angew. Chem. Int. Ed. 2020, 59, 9120.

[34] P. M. Chapple, M. Cordier, V. Dorcet, T. Roisnel, J.-F. Carpentier, Y. Sarazin, Dalton Trans. 2020, 49, 11878.

[35] K. G. Caulton, M. H. Chisholm, S. R. Drake, K. Folting, J. Chem. Soc., Chem Commun. 1990, 1349.

[36] K. F. Tesh, D. J. Burkey, T. P. Hanusa, J. Am. Chem. Soc. 1994, 116, 2409.

[37] X. Shi, C. Hou, C. Zhou, Y. Song, J. Cheng, Angew. Chem. Int. Ed. 2017, 56, 16650.

[38] X. Shi, G. Qin, Y. Wang, L. Zhao, Z. Liu, J. Cheng, Angew. Chem. Int. Ed. 2019, 58, 4356.

[39] For a soluble Ba-H cluster supported by polyamines, see: M. Wiesinger, B. Maitland, C. Färber, G. Ballmann, C. Fischer, H. Elsen, S. Harder, Angew. Chem. Int. Ed. 2017, 56, 16654.

[40] D. C. Bradley, R. C. Mehrotra, I. P. Rothwell, A. Singh, Alkoxo and Aryloxo Derivatives of Metals, 2001, Academic Press.

[41] O. Poncelet, L. G. Hubert-Pfalzgraf, L. Toupet and J.-C. Daran, Polyhedron 1991, 10, 2045.

[42] S. R. Drake, W. E. Streib, K. Folting, M. H. Chisholm, K. G. Caulton, Inorg. Chem. 1992, 31, 3205 .

[43] J. Utko, S. Szafert, L. B. Jerzykiewicz, P. Sobota, Inorg. Chem. 2005, 44, 5194.

[44] W. D. Buchanan, M. A. Guino-o, K. Ruhlandt-Senge, Inorg. Chem. 2010, 49, 7144.

[45] K. F. Tesh, T. P. Hanusa, J. C. Huffman, C. J. Huffman, Inorg. Chem. 1992, 31, 5572.

[46] G. B. Deacon, C. M. Forsyth, P. C. Junk, J. Organomet. Chem. 2000, 607, 112.

[47] W. A. Wojtczak, M. J. Hampden-Smith, E. N. Duesler, Inorg. Chem. 1996, 35, 6638.

[48] J. A. Darr, S. R. Drake, D. J. Williams, A. M. Z. Slawin, J. Chem. Soc., Chem Commun. 1990, 866.

[49] H. Roueindeji, A. Ratsifitahina, T. Roisnel, V. Dorcet, S. Kahlal, J.-Y. Saillard, J.-F. Carpentier, Y. Sarazin, Chem. Eur. J. 2019, 25, 8854.

[50] S. C. Cole, M. P. Coles, P. B. Hitchcock, Organometallics 2004, 23, 5159.

[51] A.-F. Pécharman, M. S. Hill, M. F. Mahon, Angew. Chem. Int. Ed. 2018, 57, 10688.

[52] M. P. Coles, Coord. Chem. Rev. 2016, 323, 52.

[53] S. Al-Hashimi, J. D. Smith, J. Organomet. Chem. 1978, 153, 253.

[54] H. C. Brown, V. H. Dodson, J. Am. Chem. Soc. 1957, 79, 2302.

[55] H. Chen, P. P. Power, S. C. Shoner, Inorg. Chem. 1991, 30, 2884.

[56] V. C. Gibson, C. Redshaw, W. Clegg, M. R. J. Elsegood, Polyhedron 1997, 16, 2637.

[57] R. D. Chambers, T. J. Chivers, Chem. Soc. 1964, 4782.

[58] R. D. Chambers, T. J. Chivers, Chem. Soc. 1965, 3933.

[59] D. J. Parks, W. E. Piers, G. P. A. Yap, Organometallics 1998, 17, 5492.

[60] T. Beringhelli, G. D’Alfonso, D. Donghi, D. Maggioni, P. Mercandelli, A. Sironi, Organometallics 2003, 22, 1588. 
[61] W. D. Buchanan, D. G. Allis, K. Ruhlandt-Senge, Chem. Commun. 2010, 46, 4449.

[62] A. G. M. Barrett, M. R. Crimmin, M. S. Hill, P. B. Hitchcock, P. A. Procopiou, Angew. Chem. Int. Ed. 2007, 46, 6339.

[63] M. Gärtner, H. Görls, M. Westerhausen, Dalton Trans. 2008, 1574.

[64] M. L. Cole, G. B. Deacon, C. M. Forsyth, P. C. Junk, K. M. Proctor, J. L. Scott, C. R. Strauss, Polyhedron 2007, 26, 244.

[65] B. Liu, T. Roisnel, Y. Sarazin, Inorg. Chim. Acta 2012, 380, 2.

[66] CSD Version 5.41 (November 2019).

[67] Relevant examples: for $\left[\mathrm{Ba}_{6}(\mathrm{OH})\left(\mathrm{O}^{t} \mathrm{Bu}\right)_{10}\left(\mathrm{OCEt}_{2} \mathrm{CH}_{2} \mathrm{OH}\right)\left({ }^{\mathrm{B}} \mathrm{BuOH}\right)(\text { thf })_{3}\right]$, see reference 35; for the cubic-like tetramer $\left[\mathrm{Ba}\left(\mathrm{O}^{\mathrm{t}} \mathrm{Bu}\right)_{2}\left({ }^{\mathrm{t}} \mathrm{BuOH}\right)_{2}\right]_{4}$, see: B. Borup, J. A. Samuels, W. E. Streib, K. G. Caulton, Inorg. Chem. 1994, 33, 994.

[68] M. Veith, S. Mathur, V. Huch, T. Decker, Eur. J. Inorg. Chem. 1998, 13272.

[69] C. A. Fischer, A. Rösch, H. Elsen, G. Ballmann, M. Wiesinger, J. Langer, C. Färber, S. Harder, Dalton Trans. 2019, 48, 6757.

[70] M. Westerhausen, W. Schwarz, Z. Anorg. Allg. Chem. 1992, 609, 39.

[71] M. Westerhausen, W. Schwarz, Z. Anorg. Allg. Chem. 1991, 604, 127.

[72] M. Westerhausen, W. Schwarz, Z. Anorg. Allg. Chem. 1991, 606, 177.

[73] B. A. Vaartstra, J. C. Huffman, W. E. Streib, K. G. Caulton, Inorg. Chem. 1991, 30, 121.

[74] I.-T. Moraru, F. Teleanu, G. Nemes, J. Phys. Chem. A 2020, 124, 8246.

[75] J. B. Levy, M. Hargittai, J. Phys. Chem. A 2000, 104, 1950.

[76] M. Kaupp, P. v. R. Schleyer, H. Stoll, H. Preuss, J. Chem. Phys. 1991, 94, 1360.

[77] M. Kaupp, P. v. R. Schleyer, H. Stoll, H. Preuss, J. Am. Chem. Soc. 1991, 113, 6012.

[78] M. Kaupp, P. v. R. Schleyer, J. Am. Chem. Soc. 1992, 114, 491.

[79] K. J. Kelling, R. Hoffmann, J. Am. Chem. Soc. 2006, 128, 11236.

[80] P. Garcia-Fernandez, I. B. Bersuker, J. E. Boggs, J. Phys. Chem. A 2007, 111, 10409.

[81] M. Kaupp, P. v. R. Schleyer, M. Dolg, H. Stoll, J. Am. Chem. Soc. 1992, 114, 8202.

[82] S. Grimme, J. Comput. Chem. 2006, 27, 1787.

[83] S.-C. Roşca, C. Dinoi, E. Caytan V. Dorcet, M. Etienne, J.-F. Carpentier, Y. Sarazin, Chem. Eur. J. 2016, 22, 6505. 
Alkaline Earth Metals

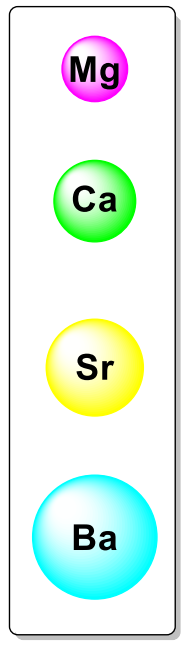

Boryloxides

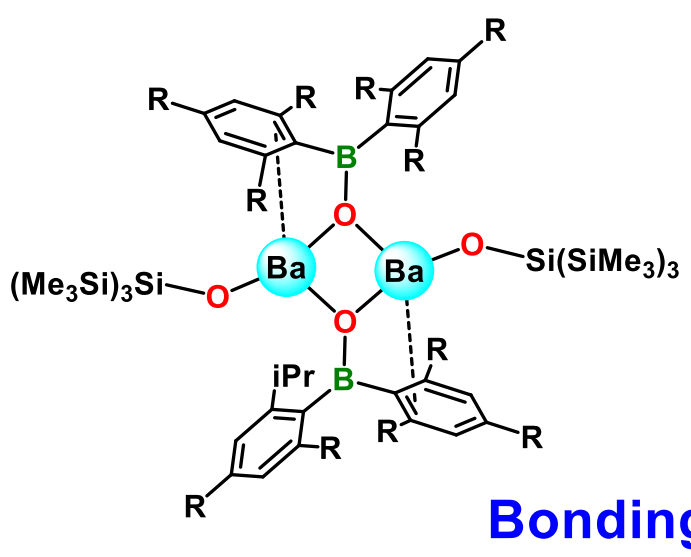

XRD

\section{Siloxides}

Phenoxides

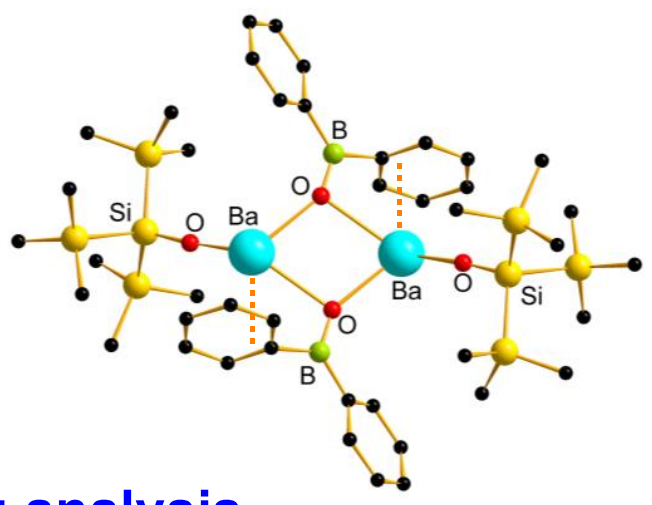
DFT

Barium and related alkaline-earth complexes bearing combinations of boryloxides, siloxides, phenoxides and amides have been structurally authenticated. Their structural patterns and bonding properties have been thoroughly investigated by DFT calculations. 